\title{
14. SPATIAL AND TEMPORAL VARIABILITY OF LATE NEOGENE EQUATORIAL PACIFIC CARBONATE: LEG 138 1
}

\author{
T.K. Hagelberg, ${ }^{2,3}$ N.G. Pisias, ${ }^{2}$ L.A. Mayer ${ }^{4}$ N.J. Shackleton, ${ }^{5}$ and A.C. $M i x^{2}$
}

\begin{abstract}
High-resolution, continuous records of GRAPE wet bulk density (a carbonate proxy) from Ocean Drilling Program Leg 138 provide one the opportunity for a detailed study of eastern equatorial Pacific Ocean carbonate sedimentation during the last $6 \mathrm{~m}$.y. The transect of sites drilled spans both latitude and longitude in the eastern equatorial Pacific from $90^{\circ}$ to $110^{\circ} \mathrm{W}$ and from $5^{\circ} \mathrm{S}$ to $10^{\circ} \mathrm{N}$. Two modes of variability are resolved through the use of Empirical Orthogonal Function (EOF) analysis. In the presence of large tectonic and climatic boundary condition changes over the last 6 m.y., the dominant mode of spatial variability in carbonate sedimentation is remarkably constant. The first mode accounts for over $50 \%$ of the variance in the data, and is consistent with forcing by equatorial divergence. This mode characterizes both carbonate concentration and carbonate mass accumulation rate time series. Variability in the first mode is highly coherent with insolation, indicating a strong linear relationship between equatorial Pacific carbonate sedimentation and Milankovitch variability. Frequency domain analysis indicates that the coupling to equatorial divergence in carbonate sedimentation is strongest in the precession band (19-23 k.y.) and weakest though present at lower frequencies.

The second mode of variability has a consistent spatial pattern of east-west asymmetry over the past $4 \mathrm{~m} . \mathrm{y}$. only; prior to 4 $\mathrm{Ma}$, a different mode of spatial variability may have been present, possibly suggesting influence by closure of the Isthmus of Panama or other tectonic changes. The second mode of variability may indicate influence by $\mathrm{CaCO}_{3}$ dissolution. The second mode of variability is not highly coherent with insolation.

Comparison of the modes of carbonate variability to a $4 \mathrm{~m} . \mathrm{y}$. record of benthic $\delta^{18} \mathrm{O}$ indicates that although overall correlation between carbonate and $\delta^{18} \mathrm{O}$ is low, both modes of variability in carbonate sedimentation are coherent with $\delta^{18} \mathrm{O}$ changes at some frequencies. The first mode of carbonate variability is coherent with Sites $846 / 849 \delta^{18} \mathrm{O}$ at the dominant insolation periods, and the second mode is coherent at $100 \mathrm{k} . \mathrm{y}$. during the last $2 \mathrm{~m} . \mathrm{y}$. The coherence between carbonate sedimentation and $\delta^{18} \mathrm{O}$ in both EOF modes suggests that multiple uncorrelated modes of variability operated within the climate system during the late Neogene.
\end{abstract}

\section{INTRODUCTION AND SCIENTIFIC BACKGROUND}

Because the oceanic carbon reservoir is 60 times the size of the atmosphere and is in direct exchange with the atmosphere, orbital scale atmospheric $\mathrm{CO}_{2}$ changes must ultimately be explained by changes in the oceanic carbon cycle (Broecker and Peng, 1982). Evidence from ice cores indicates that the $\mathrm{CO}_{2}$ increase at the ends of glacial periods occurred rapidly, on the order of a thousand years. To understand this process, it is necessary to understand the mechanisms controlling the carbon cycle on glacial/interglacial time scales. While ice cores provide a direct measure of changes in atmospheric $\mathrm{CO}_{2}$, examination of the marine sediment record is necessary to obtain a history beyond that of the last glacial cycle.

Efforts to understand the mechanisms through which the oceanic carbon cycle changes atmospheric $\mathrm{CO}_{2}$ have led to years of carbon cycle modeling. Hypotheses for glacial/interglacial $\mathrm{pCO}_{2}$ changes were grouped into four categories by Heinze et al. (1991) in a recent overview: three kinds of oceanic carbon pumps that are capable of influencing atmospheric $\mathrm{CO}_{2}$ (a solubility pump, a nutrient pump, and a $\mathrm{CaCO}_{3}$ pump), and changes in the oceanic velocity field and ventilation rates. Evidence for oceanic carbon pool changes that is needed to evaluate hypotheses is derived primarily from sedimentary $\delta^{13} \mathrm{C}$ and $\mathrm{CaCO}_{3}$ records. $\delta^{13} \mathrm{C}$ indicates the efficiency of the ocean's biological pump and the nutrient content of deep and surface waters. The $\mathrm{CaCO}_{3}$ concentration in sediments reflects productivity, dilution, and alkalinity changes.

'Pisias, N.G., Mayer, L.A., Janecek, T.R., Palmer-Julson, A., and van Andel. T.H. (Eds.), 1995. Proc. ODP Sci. Results, 138: College Station TX (Ocean Drilling Program)

${ }^{2}$ College of Oceanic and Atmospheric Sciences, Oregon State University, Corvallis, OR U.S.A.

${ }^{3}$ Now at Graduate School of Oceanography, University of Rhode Island, Narragansett, RI U.S.A.

${ }^{4}$ Institute for Ocean Mapping, University of New Brunswick, Fredericton, N.B., Canada.

${ }^{5}$ Subdepartment of Quaternary Research, Godwin Laboratory, Cambridge University, Cambridge, United Kingdom.
The extent to which $\mathrm{CaCO}_{3}$ sedimentation in equatorial Pacific Ocean sediments has been controlled by production or dissolution has been the subject of debate for more than $40 \mathrm{yr}$. Since Arrhenius (1952), studies have investigated the relationship of equatorial Pacific carbonate sedimentation to regional surface processes, global glacial/ interglacial changes, and external orbital (Milankovitch) influence (e.g., Hays et al., 1969, Moore et al., 1977, 1982; Farrell and Prell, 1989; Rea et al., 1991). In the equatorial Pacific Ocean, large changes in sedimentary calcium carbonate concentration have occurred on long time scales (millions of years), as a response to oceanic boundary condition and geochemical mass budget changes, and on shorter time scales (tens of thousands of years), as a response to climatic influence.

Changing boundary conditions during the late Cenozoic have significantly influenced equatorial Pacific sediment composition. van Andel et al. (1975) estimated the initiation of the Equatorial Undercurrent (EUC) at about 11 to $12 \mathrm{Ma}$, when the northward movement of the Australia Plate cut off western Pacific-Indian Ocean circulation. This development may have caused the onset of a narrow, equatorially symmetric zone of carbonate and opal sedimentation having steep gradients away from the equator. Widespread orogeny during the late Miocene and Pliocene may have had a large influence on oceanic alkalinity budgets through increased chemical weathering (Raymo et al., 1988). This uplift may have also influenced surface ocean circulation in the equatorial Pacific through associated changes in atmospheric circulation (Ravelo et al., 1992). A modeling study has suggested that prior to closure of the Isthmus of Panama (3-4 Ma or earlier), North Atlantic Deep Water (NADW) production was reduced, carbonate preservation was increased because of less undersaturated Pacific deep waters, and eastern equatorial Pacific surface upwelling was unchanged (Maier-Raimer et al., 1990). Initiation of large-scale continental glaciation in the Northern Hemisphere near 2.4 Ma may have altered oceanic alkalinity and productivity significantly.

van Andel et al. (1975) demonstrated that similar spatial patterns are present in bulk-sediment accumulation rates, carbonate accumulation rates, and carbonate concentration of central equatorial Pacific 
Ocean sediments throughout the Cenozoic. A high correlation of these variables with latitude reflected the "bulge" of equatorial Pacific productivity. Longitudinal gradients in carbonate accumulation across the central equatorial Pacific were small by comparison. Their results implied that the equatorial calcite compensation depth $(\mathrm{CCD})$ has fluctuated by only a few hundred meters over the past $35 \mathrm{~m}$.y. This constancy in the depth of the CCD requires that large changes in the gradient of $\mathrm{CaCO}_{3}$ dissolution be compensated for by variations in lysocline depth and carbonate supply from surface waters.

On shorter time scales, regional studies have demonstrated that the depth and slope of the lysocline in the central equatorial Pacific Ocean changed dramatically over glacial and interglacial cycles. During the late Pleistocene in the equatorial Pacific, glacial intervals recorded higher $\mathrm{CaCO}_{3}$ concentration and accumulation than interglacial periods (Farrell and Prell, 1989; Berger, 1973). If changes in deep ocean carbonate ion saturation produced the glacial increase, according to Archer's model (1991a), a large $(20-40 \mu \mathrm{m})$ change in the gradient of $\mathrm{CaCO}_{3}$ saturation must have occurred over a fairly small $(\sim 100 \mathrm{~m})$ depth interval. On the other hand, if changes in surface water carbonate production produced the glacial carbonate increase, the gradient in $\mathrm{CaCO}_{3}$ saturation would have remained relatively homogeneous with depth. To explain increased glacial carbonate concentration and accumulation through productivity changes, Archer's model requires a doubling of productivity during the last glacial relative to the present. This estimate is consistent with independent estimates of glacial surface production in equatorial oceans (e.g., Mix, 1989; Finney et al., 1988; Prahl et al., 1989; Lyle et al., 1988).

Regardless of whether deep ocean or surface ocean processes are primarily responsible for the observed changes in equatorial Pacific carbonate sedimentation on 10- to 100-k.y. scales, a temporal association with Pleistocene glacial/interglacial changes is well known. Moore et al. (1977) documented a 6 to 8-k.y. lag between ice volume and $\mathrm{CaCO}_{3}$ concentration in the equatorial Pacific. Farrell and Prell (1989) documented a similar relationship in a reconstruction of late Pleistocene central equatorial Pacific lysocline changes. This lag is thought to result from the response time of oceanic $\mathrm{CO}_{3}^{=}$compensation of glacial/interglacial $\mathrm{TCO}_{2}$ changes (Broecker and Peng, 1982). However, in detail the ice volume-carbonate relationship is not straightforward. While some studies have shown carbonate variations during the late Pleistocene to be coherent with ice volume variations (Rea et al., 1991; Farrell and Prell, 1989; Luz and Shackleton, 1975), others have indicated either no relationship or a complex one (e.g., Moore et al., 1982; Pisias and Rea, 1988, Lyle et al., 1988). Spatial variability in carbonate sedimentation, as noted by Murray (1987) and Farrell and Prell $(1989,1991)$, probably contributes to the different conclusions reached by studies that focused on selected locations.

Time series studies spanning intervals beyond the late Pleistocene indicate a complex relationship between equatorial Pacific carbonate and ice volume. For instance, a comparison of carbonate and ice volume proxy $\left(\delta^{18} \mathrm{O}\right)$ records spanning the past $4 \mathrm{~m}$.y. (Farrell and Prell, 1991) suggests that the relationship between equatorial Pacific lysocline fluctuations and ice volume is not straightforward. It is well known that a change in the amplitude of global ice volume variability from principally 41 k.y. oscillations to 100 k.y. oscillations occurred near 1 Ma (Ruddiman et al., 1989; Raymo et al., 1989; Pisias and Moore, 1981). A corresponding change in the amplitude of $\mathrm{CaCO}_{3}$ variability is not evident from in Farrell and Prell's data. Although low sedimentation rates and uncertainties in chronology have made it difficult to determine how $\mathrm{CaCO}_{3}$ and $\delta^{18} \mathrm{O}$ have covaried over the past 4 m.y. in the equatorial Pacific, the records compared by Farrell and Prell suggest that the relationships observed in late Pleistocene age sediments were not present during the early Pleistocene and Pliocene.

\section{RESEARCH STRATEGY}

The following generalities can be made from the above information: (1) despite many studies, the relationship between equatorial
Pacific carbonate sedimentation and global climate changes over the past several million years is not well defined. Strong spatial variability probably contributes; (2) the debate over production vs. dissolution as a control on eastern equatorial Pacific carbonate sedimentation is not resolved; and (3) most previous studies were limited to data sets restricted in either spatial coverage or temporal resolution.

The suite of sites sampled during Leg 138 provide additional high resolution carbonate and $\delta^{18} \mathrm{O}$ records from the equatorial Pacific which can clarify these relationships. These records provide (1) spatial coverage of a very dynamic region; (2) high temporal sampling resolution (order of 1-2 k.y.); (3) long temporal coverage (>6 m.y.); (4) an internally consistent chronology; and (5) high-quality proxy records.

The objective of the present study is to determine if effects on carbonate sedimentation resulting from surface ocean processes, which will be more regional in nature, can be discriminated from effects caused by changes in deep ocean chemistry, which will be more uniform in nature. Two longitudinal transects of sites cross the high productivity region of the equatorial Pacific, allowing for comparison of latitudinal and (to a limited extent) longitudinal gradients of this system (Fig. 1). The latitudinal and longitudinal positions of the drilled sites have changed by no more than $0.5^{\circ}$ latitude and $4^{\circ}$ longitude over the past $6 \mathrm{~m}$.y. due to west-northwest movement of the Pacific Plate (Pisias et al., this volume). The sites are at water depths within the lysocline ( $3200 \mathrm{~m}$, Parker and Berger, 1971; Adelseck and Anderson, 1978) and above the calcite saturation horizon ( 4000 m, Broecker and Peng, 1982) (Table 1). While data are located at different depths, no correlation exists for depth vs. latitude that would complicate determination of whether changes in carbonate result from changes in productivity or from changes in lysocline depth (Fig. 2 and Table 1). These sites are shallower than the sites studied by Farrell and Prell (1991). However, because the equatorial Pacific lysocline also shoals to the east, these two data sets are comparable with respect to upper lysocline fluctuations.

In this study, carbonate proxy records from gamma-ray attenuation porosity evaluator (GRAPE; Boyce, 1976) wet-bulk density measurements at Sites 846 through 853 were analyzed. Site 844 , located in the Costa Rica Dome, and Site 845 , located in the Guatemala Basin, represent different oceanographic environments and were dominantly siliceous clay during much of the late Neogene and were not considered in the present study. The continuity of the records from Sites 846 through 853 is documented in detail over the last 6

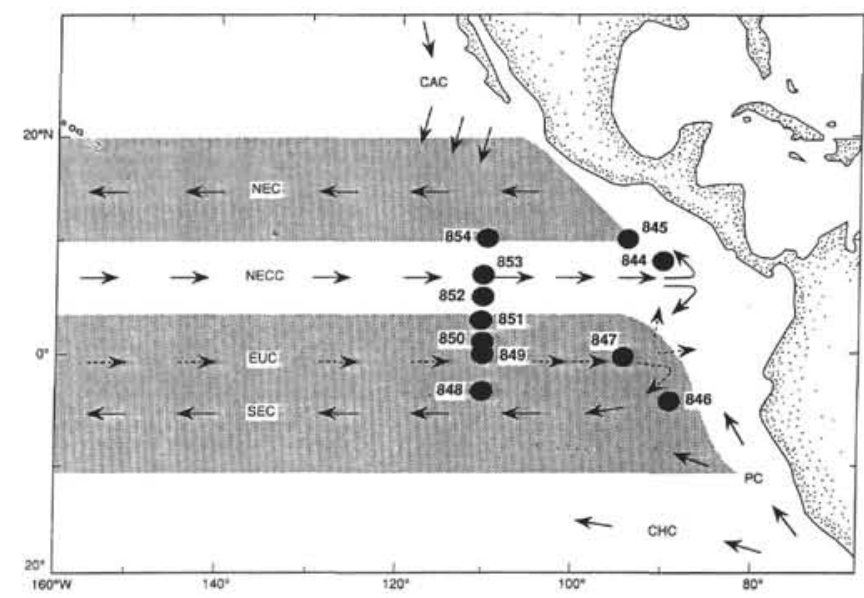

Figure 1.Present-day location of Leg 138 Sites 844 through 854, superimposed on a schematic of the general circulation of the eastern equatorial Pacific Ocean. Solid arrows indicate surface currents, and dashed arrow indicates the Equatorial Undercurrent (EUC). Shaded regions illustrate the latitudinal extent of the South Equatorial Current (SEC) and North Equatorial Current (NEC). $\mathrm{NECC}=$ North Equatorial Countercurrent $\mathrm{CAC}=$ California Current $\mathrm{CHC}=$ Chile Current; and PC = Peru Current. 
Table 1. Present locations and water depths of Leg 138 Sites 846 through 853.

\begin{tabular}{cccc}
\hline Site & Latitude & Longitude & $\begin{array}{c}\text { Depth } \\
(\mathrm{m})\end{array}$ \\
\hline 846 & $3.05^{\circ} \mathrm{S}$ & $90.49^{\circ} \mathrm{W}$ & 3307 \\
847 & $0.11^{\circ} \mathrm{N}$ & $95.19^{\circ} \mathrm{W}$ & 3346 \\
848 & $2.59^{\circ} \mathrm{S}$ & $110.28^{\circ} \mathrm{W}$ & 3867 \\
849 & $0.10^{\circ} \mathrm{N}$ & $110.31^{\circ} \mathrm{W}$ & 3850 \\
850 & $1.17^{\circ} \mathrm{N}$ & $110.31^{\circ} \mathrm{W}$ & 3797 \\
851 & $2.46^{\circ} \mathrm{N}$ & $110.34^{\circ} \mathrm{W}$ & 3772 \\
852 & $5.17^{\circ} \mathrm{N}$ & $110.04^{\circ} \mathrm{W}$ & 3872 \\
853 & $7.12^{\circ} \mathrm{N}$ & $109.45^{\circ} \mathrm{W}$ & 3726 \\
\hline
\end{tabular}

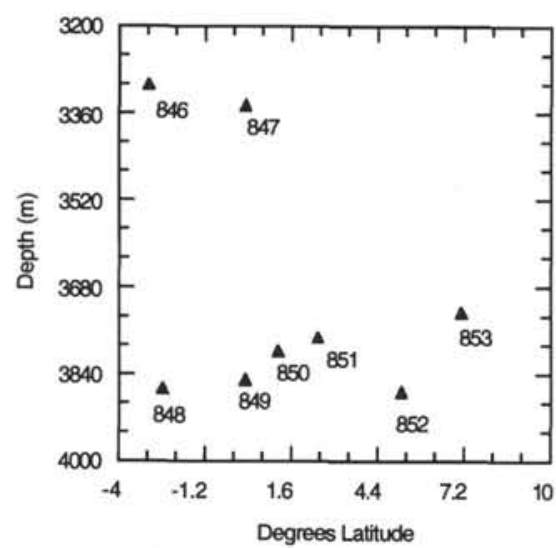

Figure 2. Sites 846 through 853 vs. present-day water depth. A large difference in depth occurs between the eastern transect ( 846 and 847) and western transect sites (848-853), small differences are seen among the western transect sites. No strong depth-latitude correlation is seen.

Time series of predicted carbonate concentrations and mass accumulation rates (MAR) were determined using the orbitally calibrated chronology of Shackleton et al. (this volume). Uncorrelated modes of spatial variability were resolved using empirical orthogonal function (EOF) analysis. Linear relationships between solar insolation and carbonate variability were explored through the use of cross-spectral analyses. The temporal evolution of carbonate sedimentation was studied in 1-m.y. time steps. Analysis of individual frequency bands provided additional information regarding processes responsible for carbonate variability. These results are related to sedimentary carbonate concentration (\%), which is influenced by dilution from opal and nonbiogenic material. To investigate variability of carbonate sedimentation independent of opal fluctuations, carbonate MAR time series were analyzed. Finally, these results were used to examine interactions between carbonate sedimentation and global ice volume variations over the past $4.6 \mathrm{~m} . \mathrm{y}$

\section{METHODS}

\section{Continuous Records}

Each of the 11 Leg 138 drill sites was multiple-APC cored in an effort to document recovery of a continuous sedimentary sequence. At each site, records of magnetic susceptibility, GRAPE wet-bulk density, and sediment color reflectance were used to monitor section recovery and to construct a composite depth section (Hagelberg et al., 1992; Mayer, Pisias, Janecek, et al., 1992). Multiple measurements of these sedimentary parameters on adjacent holes provide multiple realizations of the same sedimentary process at every site. The GRAPE records from each hole at Sites 846 through 852 were

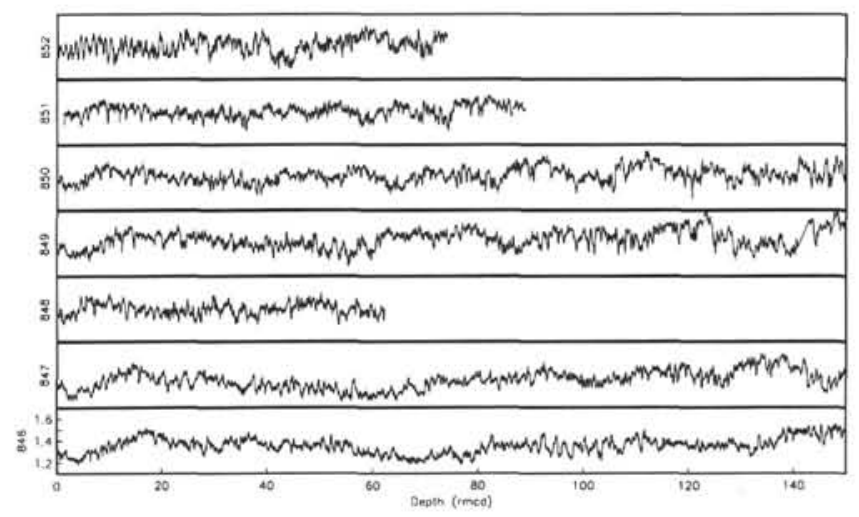

Figure 3. Stacked GRAPE wet-bulk density records from Sites 846 through 852. $y$-axis scale is indicated at bottom.

'stacked' to provide a statistically robust and less noisy estimate of sediment bulk density (Hagelberg et al., this volume). The average sampling interval of the stacked, smoothed GRAPE records is $2 \mathrm{~cm}$ (Fig. 3). The temporal resolution of the records is on the order of 1000 yr.

\section{GRAPE Data as a Carbonate Proxy}

Sample resolution traditionally has been a problem when studying pre-Pleistocene spatial and temporal climatic variations at high resolution because of time and cost restrictions. During Leg 138, this problem was addressed through the use of $\mathrm{CaCO}_{3}$ proxy records derived from GRAPE bulk density at near-continuous resolution at all sites. Development of proxy $\mathrm{CaCO}_{3}$ estimates was possible because equatorial Pacific sediments are primarily composed of two components: biogenic calcite and opal. Owing to this composition, bulk density is a good predictor of carbonate in this region (Mayer, 1991; Herbert and Mayer, 1991). Wet-bulk density measurements record two primary differences between carbonate and opal: their grain densities and their packing properties. These relationships led to development of an empirical relationship that predicts carbonate on this basis (Mayer, 1979, 1991). After correction to account for porosity rebound and depth, Mayer's (1991) equation was used to predict carbonate concentration at Sites 846 through 853:

$$
\% \mathrm{CaCO}_{3}=-835.52+1112.69 \rho-332.54 \rho^{2}
$$

The second term in the above equation reflects the linear graindensity relationship, and the last term reflects the nonlinear packing factor. Herbert and Mayer (1991) demonstrated that the sensitivity of sedimentary wet-bulk density to $\mathrm{CaCO}_{3}$ concentration is controlled by the high porosity of the noncarbonate (opal) fraction. Thus, although biogenic opal has a lower grain density than carbonate (2.1$2.3 \mathrm{~g} / \mathrm{cm}^{3}$, as compared to $2.6-2.7 \mathrm{~g} / \mathrm{cm}^{3}$; Mayer, 1979), porosity differences are most important.

Stacked GRAPE records developed from the adjacent holes at each site (Hagelberg et al., this volume; Fig. 3) and a spliced record from Site 853 were used in the carbonate predictions. The effectiveness of GRAPE data as a carbonate predictor is indicated by the scatter plots in Figure 4, which compare shipboard $\mathrm{CaCO}_{3}$ measurements to predicted values from matching samples in Sites 846 through 853. The sample cross correlation, or model skill, that gives the fraction of variance explained by the predictive model, is shown in Table 2. (This calculation assumes that the measured $\mathrm{CaCO}_{3}$ values have no error.) At each site, the correlation is significant at a level of 0.99 . Root mean square error ranges from 5.3 at Site 853 to 10.2 at Site 846. 
846

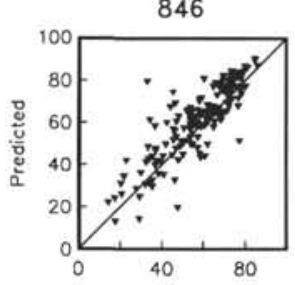

850

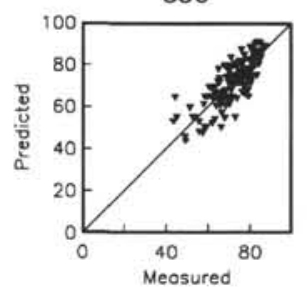

847

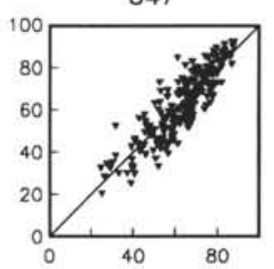

851

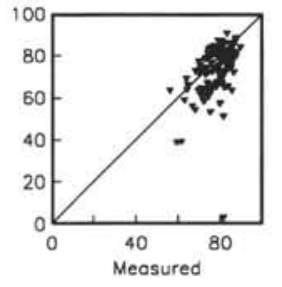

848

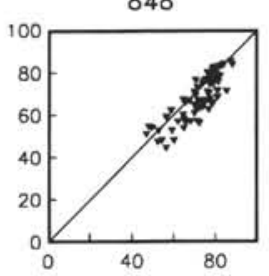

852

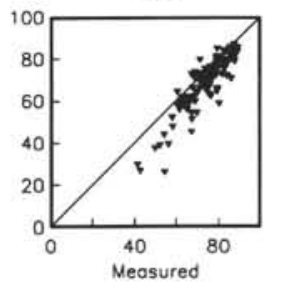

849

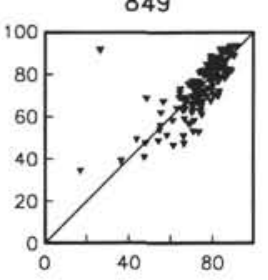

853

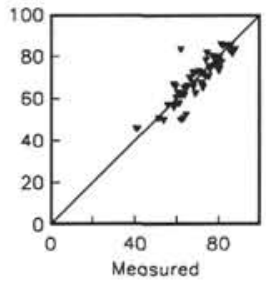

Figure 4. Scatter plots of predicted (from GRAPE) vs. measured $\% \mathrm{CaCO}_{3}$ from the top 6 m.y. of Sites 846 through 853.

\section{Chronology}

The correlatability of GRAPE records over the Leg 138 sites contributed to development of an internally consistent chronostratigraphic framework for Leg 138 sites during the cruise (Shackleton et al., 1992). A series of events, identified primarily on the basis of biostratigraphy and magnetostratigraphy, were related to patterns in the GRAPE bulk density records. Correlations between the GRAPE bulk density records were used to identify these events at every site. During post-Leg 138 study, Shackleton et al. (this volume) demonstrated that very high stratigraphic resolution is possible if the assumptions of an orbitally driven system are considered. Variations in GRAPE and $\delta^{18} \mathrm{O}$ were correlated to variations in $65^{\circ} \mathrm{N}$ solar insolation (as determined by Berger and Loutre, 1988) to develop a chronology that is both internally consistent and astronomically calibrated over the past 6 m.y. (Shackleton et al., this volume).

Because no a priori model was available for predicting appropriate time constants for the response of equatorial Pacific carbonate to orbital forcing, zero phase between insolation and GRAPE was initially assumed (Shackleton et al., this volume). The further assumption that correlatable GRAPE events at all sites were in phase with one another was necessary to correlate the records at high resolution. These assumptions have bearing on the resulting time-varying spatial variability in the carbonate records. As measurements of benthic $\delta^{18} \mathrm{O}$ from multiple sites emerged, providing independent measurements that were spatially in phase, the assumption of no phase difference between individual GRAPE events was modified and the astronomically calibrated chronology was adjusted accordingly (Shackleton, et al, this volume). Because the GRAPE-calibrated $\left(\delta^{18} \mathrm{O}\right.$ independent) chronology and the chronology developed using $\delta^{18} \mathrm{O}$ data have slight differences in some intervals (on the order of a few thousand years),

Table 2. Statistics for predicted values of percent $\mathrm{CaCO}_{3}$ compared with measured values, Sites 846 through 853 .

\begin{tabular}{|c|c|c|c|c|c|c|c|c|}
\hline \multirow[b]{2}{*}{ Site } & \multirow[b]{2}{*}{$\mathrm{N}$} & \multicolumn{2}{|c|}{ Measured \% $\mathrm{CaCO}_{3}$} & \multicolumn{2}{|c|}{ Predicted $\% \mathrm{CaCO}_{3}$} & \multirow[b]{2}{*}{ Skill $^{a}$} & \multirow[b]{2}{*}{ Crit. val. ${ }^{b}$} & \multirow[b]{2}{*}{ RMS $^{\mathrm{c}}$} \\
\hline & & Mean & Std. dev. & Mean & Std. dev. & & & \\
\hline 846 & 166 & 57.7 & 16.2 & 61.9 & 17.2 & 0.85 & 0.24 & 8.85 \\
\hline 847 & 227 & 63.1 & 13.6 & 62.7 & 15.4 & 0.87 & 0.20 & 7.61 \\
\hline 848 & 69 & 72.0 & 9.6 & 68.3 & 10.5 & 0.83 & 0.36 & 5.69 \\
\hline 849 & 154 & 74.7 & 11.4 & 74.9 & 12.3 & 0.74 & 0.24 & 8.21 \\
\hline 850 & 128 & 71.5 & 9.6 & 72.2 & 10.9 & 0.78 & 0.27 & 6.71 \\
\hline 851 & 123 & 77.8 & 6.5 & 73.1 & 11.6 & 0.47 & 0.27 & 10.2 \\
\hline 852 & 121 & 74.2 & 9.8 & 69.4 & 12.7 & 0.90 & 0.28 & 5.50 \\
\hline 853 & 59 & 69.4 & 10.5 & 69.3 & 10.7 & 0.86 & 0.39 & 5.32 \\
\hline
\end{tabular}

a The model skill gives the fraction of variance explained by the predictive mode.

b Crit. val. $=0.99$ level for significant skill.

c $\mathrm{RMS}=$ root-mean-square error.
Shackleton et al. (this volume) presented two alternative chronologies for the upper 1 m.y. at the Leg 138 sites. In this study, the alternative chronology that makes use of the $\delta^{18} \mathrm{O}$ data is used. The resulting time series of predicted $\mathrm{CaCO}_{3}$ concentration from Sites 846 through 853 for the interval from 0 to $6 \mathrm{Ma}$ is given in Figure 5.

\section{Mass Accumulation Rates}

Although a great deal of information can be gained from analysis of $\mathrm{CaCO}_{3}$ concentration alone, carbonate concentration is not the most sensitive indicator of carbonate dissolution (Heath and Culberson, 1970). Dilution by biogenic opal and other sedimentary components influences carbonate concentration in sediments. Farrell and Prell $(1989,1991)$ assumed that opal sedimentation in the central equatorial Pacific was sufficiently negligible and that $\mathrm{CaCO}_{3}$ concentration sufficiently approximated carbonate mass burial. In the eastern tropical Pacific Ocean, however, opal is often a significant sedimentary component. Thus, carbonate mass accumulation rates were estimated to evaluate objectively the role of opal dilution when determining spatial variability in $\mathrm{CaCO}_{3}$ concentration records.

Calculation of mass accumulation rates incorporates several sources of error. Standard errors in carbonate prediction were estimated in the preceding section (Table 2) and on average are about $7 \%$. Second, the dry-bulk density of the sediment must be known. Third, a highly constrained chronology is required to determine sedimenta-

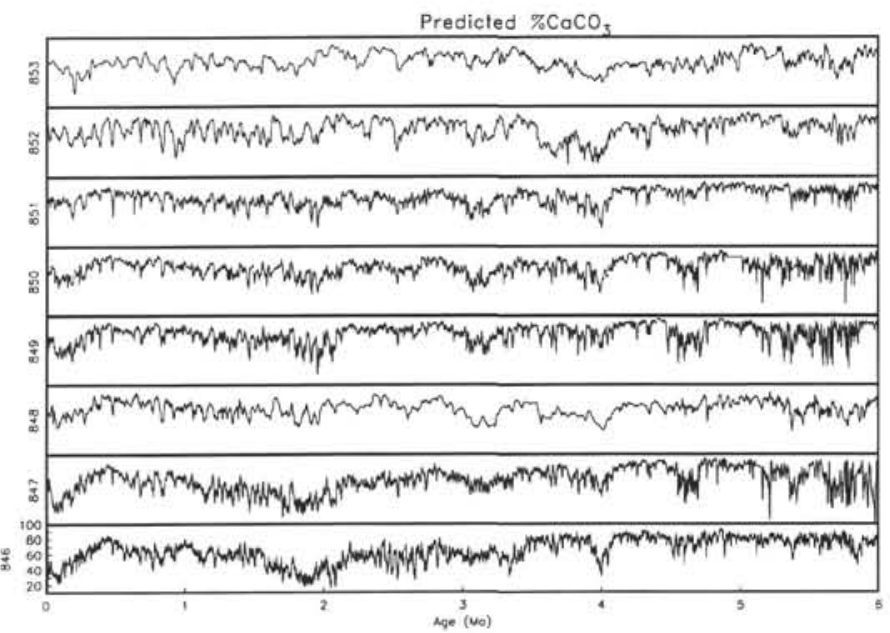

Figure 5. The 6-m.y, records of predicted $\% \mathrm{CaCO}_{3}$ for Sites 846 through 853. $y$-axis scale is indicated for Site 846. 
Table 3. Grain density statistics, Sites 846 through 853.

\begin{tabular}{crcc}
\hline Site & N & Mean & Std. dev. \\
\hline 846 & 398 & 2.50 & 0.12 \\
847 & 375 & 2.54 & 0.10 \\
848 & 115 & 2.59 & 0.08 \\
849 & 317 & 2.59 & 0.07 \\
850 & 260 & 2.60 & 0.07 \\
851 & 248 & 2.63 & 0.07 \\
852 & 135 & 2.72 & 0.05 \\
853 & 75 & 2.73 & 0.05 \\
\hline
\end{tabular}

tion rates. The cumulative errors in estimating these three parameters limits the use of mass accumulation rates.

During Leg 138, estimates of wet-bulk and dry-bulk densities, porosity, and grain density were derived from measurements of wet and dry sediment weights and sediment dry volume at $75-\mathrm{cm}$ intervals (in the same samples as shipboard $\mathrm{CaCO}_{3}$ measurements). High-resolution estimates of dry-bulk density are possible if dry-bulk density can be determined from GRAPE wet-bulk density. This is possible if sediment grain densities are known. Statistics for sediment grain densities derived from the physical property measurements are given for each site in Table 3. At any given site, the grain density is relatively uniform, having a low standard deviation. However, significant differences exist between individual sites, as mean grain densities range from $2.5 \mathrm{~g} / \mathrm{cm}^{3}$ at Site 846 to $2.7 \mathrm{~g} / \mathrm{cm}^{3}$ at Site 853 . With these estimates of grain density, GRAPE predictions of wet-bulk and dry-bulk densities and porosity were compared with measured values for each site (Fig. 6 and Table 4). The correlation between GRAPE-
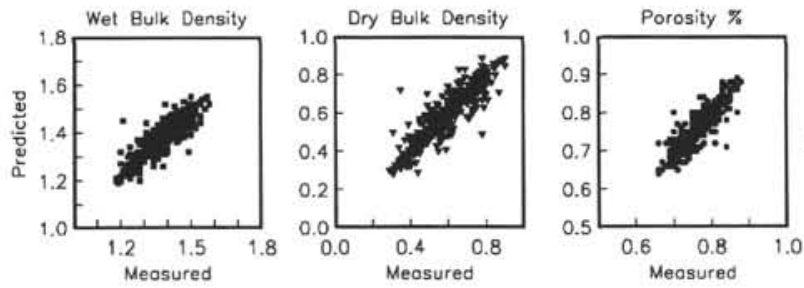

846
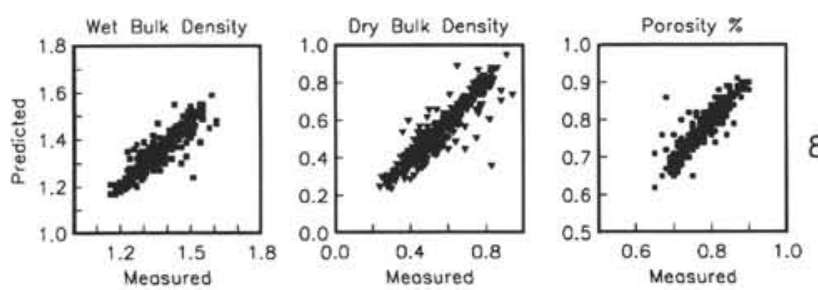

847
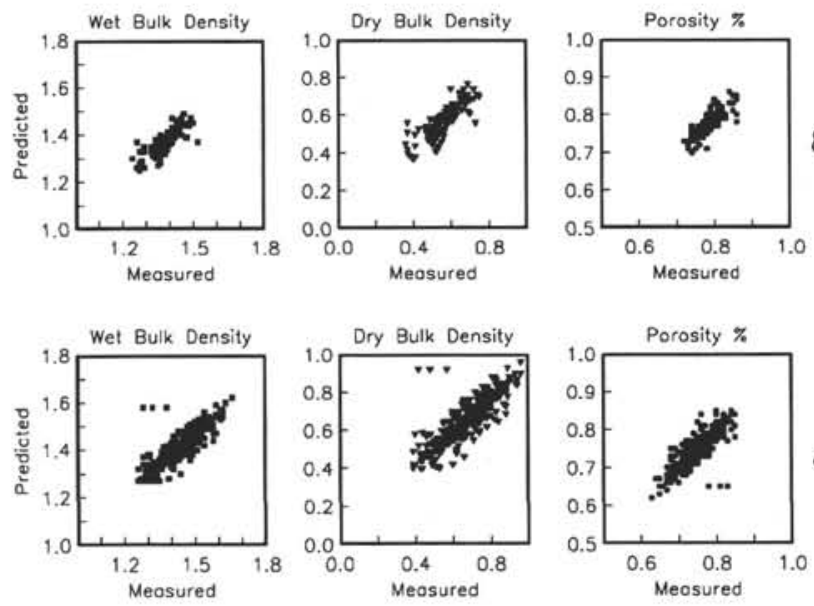

predicted and estimated values is significant at a 0.99 level for each site. Root-mean-square error ranges from 0.045 to 0.066 , on the order of $8 \%$.

Estimates of sedimentation rates have been derived directly from tie points in the astronomically calibrated chronology of Shackleton et al. (this volume). Average spacing of age control points is 25 to 30 k.y. with two exceptions: Sites 848 and 853 , which have much lower sedimentation rates. Estimates of errors in the sedimentation rates are difficult to obtain. However, comparison of the tuned chronology with variations typically seen between adjacent holes (Hagelberg et al., this volume) suggests that variability in sedimentation rates on the order of $15 \%$ are typical. Assuming that the three sources of error estimated above are uncorrelated, the total error of MAR estimates at most $7 \%+8 \%+15 \%=30 \%$. This is a rough approximation, but it serves to indicate the higher error introduced into MAR estimates. Estimates of carbonate MAR for Sites 846 through 853 for the interval 0 to 6 m.y. are given in Figure 7.

\section{EOF Analyses}

Each record from Sites 846 through 853 displays some level of variability that is common to all of the sites, as well as variability that is unique to that site. The common variability was used by Shackleton et al. (1992) as a means of correlating biostratigraphic and magnetostratigraphic events among sites, as described above. The goal of this study is to partition patterns of variability in equatorial Pacific Ocean carbonate sedimentation in a quantitative manner.

The numerical approach used to partition the eight time series from Sites 846 through 853 into a smaller set of spatial and temporal
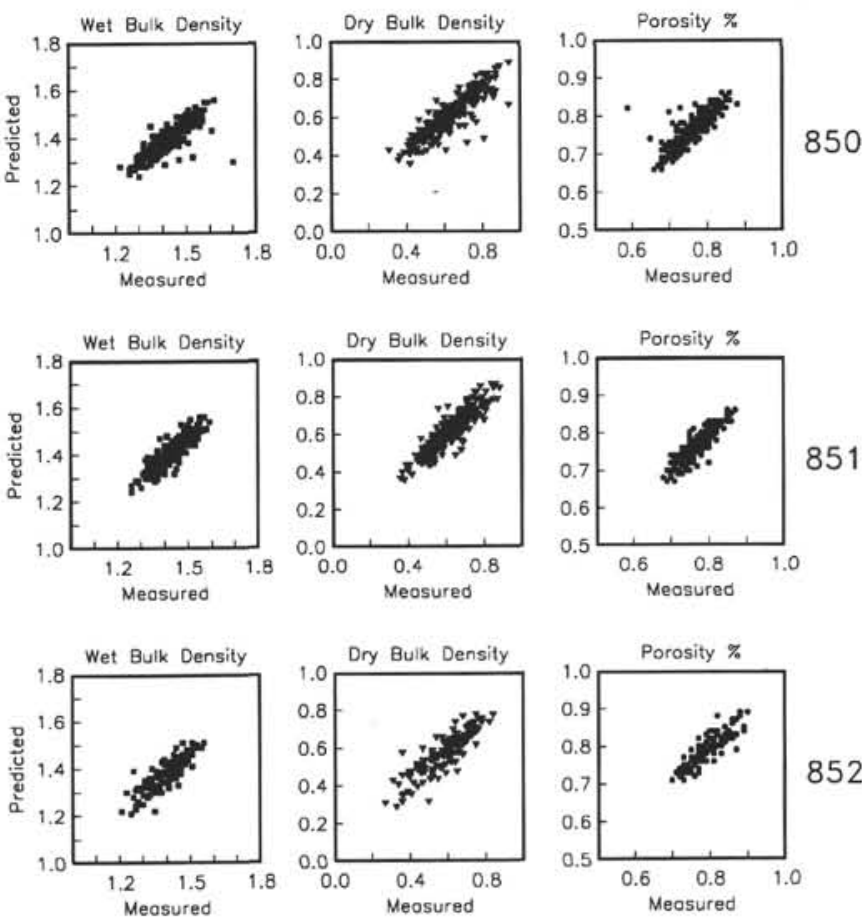

852
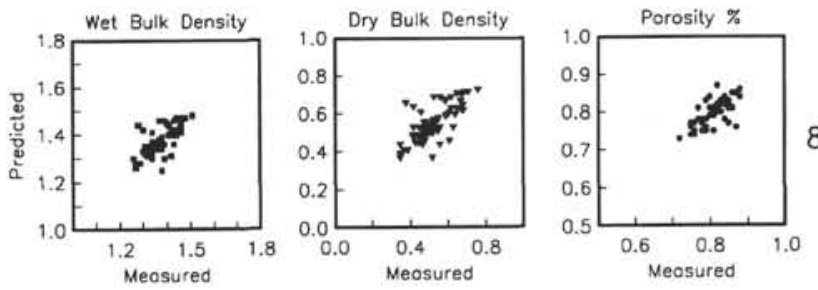

853

Figure 6. Scatter plots of predicted (from GRAPE) vs. measured wet-bulk density (squares), dry-bulk density (triangles). and porosity (circles) for Sites 846 through 853 . 
Table 4. Statistics for predicted values of dry-bulk density compared with measured values, Sites 846 through 853 . $^{\text {t }}$

\begin{tabular}{|c|c|c|c|c|c|c|c|c|}
\hline \multicolumn{4}{|c|}{ Measured dry-bulk density } & \multicolumn{5}{|c|}{ Predicted dry-bulk density } \\
\hline Site & $\mathrm{N}$ & Mean & Std. dev. & Mean & Std dev. & Skill & Crit. val." & RMS \\
\hline 846 & 398 & 0.59 & 0.14 & 0.59 & 0.14 & 0.90 & 0.15 & .059 \\
\hline 847 & 375 & 0.55 & 0.15 & 0.54 & 0.14 & 0.91 & 0.16 & .059 \\
\hline 848 & 115 & 0.57 & 0.09 & 0.58 & 0.09 & 0.83 & 0.28 & .049 \\
\hline 849 & 317 & 0.67 & 0.13 & 0.65 & 0.12 & 0.83 & 0.17 & .066 \\
\hline 850 & 260 & 0.63 & 0.12 & 0.61 & 0.11 & 0.83 & 0.19 & .059 \\
\hline 851 & 248 & 0.63 & 0.10 & 0.62 & 0.10 & 0.89 & 0.19 & .045 \\
\hline 852 & 135 & 0.58 & 0.12 & 0.57 & 0.11 & 0.86 & 0.26 & .054 \\
\hline 853 & 74 & 0.52 & 0.09 & 0.55 & 0.09 & 0.71 & 0.35 & .063 \\
\hline
\end{tabular}

The model skill gives the fraction of variance explained by the predictive mode

"Crit. val $=0.99$ level for significant skil

RMS = root-mean-square-error.

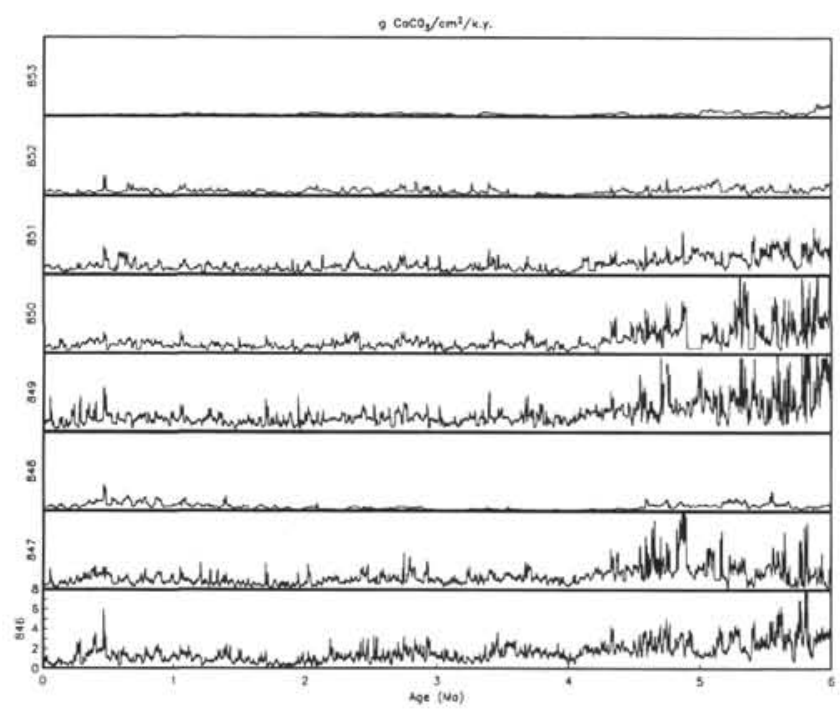

Figure 7. $\mathrm{CaCO}_{3}$ mass accumulation rates in $\mathrm{g} \mathrm{CaCO}_{3} / \mathrm{cm}^{2} / \mathrm{k}$.y., 0 to $6 \mathrm{Ma}$ for Sites 846 through 853 . See text for description of calculations. $y$-axis scale is given in the bottom panel.

patterns is known as EOF analysis. EOF analysis is a form of Principal Components Analysis commonly used in meteorology and oceanography. An extensive review of the method is provided by Preisendorfer (1988). EOF analysis is a means of representing a spatial array of time series by a finite number of independent (orthogonal) spatial modes of variability and weighted amplitude time series of these modes. In equation form,

$$
x_{m}(t)=\sum_{k=1}^{M} a_{k}(t) F_{k}(m),
$$

where $t$ is the time index $0,1,2, \ldots N$ for observations at $M$ locations ( $m$ $=1, \ldots M$ ) (in this study, $M=8$ ). The $M$ time series, represented by $x_{m}(t)$, are decomposed into a set of orthogonal functions (EOFs) $F_{k}(m)$, where $k$ is the mode number, multiplied by the amplitude of that mode at time $t, a_{k}(t)$. The simplification of this approach is that a small number of EOFs often describe most of the variability in a data set more efficiently than any other representation. Here, variability within the arrays of carbonate concentration and mass flux records from Sites 846 through 853 were studied. The EOFs were determined from the data covariance matrix.

\section{Spectral Analyses}

Power spectra and cross-spectra of the amplitude time series from the EOF analyses indicate the frequency distribution of variance of each EOF, as well as the extent to which each EOF is coherent with Milankovitch band variability. Spectral estimates were made using the Blackman-Tukey lagged auto- (or cross-) covariance method (Jenkins and Watts, 1968). Sampling intervals were $1000 \mathrm{yr}$. For analyses of the entire 6 m.y. records, 600 lags of the auto and cross-covariance and a cosine taper window were used for smoothed estimates having at least 27 degrees of freedom. For analyses of $1 \mathrm{~m} . \mathrm{y}$. intervals, 400 lags of the auto or cross covariance were used for smoothed estimates having at least 7 degrees of freedom.

\section{RESULTS AND DISCUSSION}

\section{General Patterns of Carbonate Variability (0-6 Ma)}

One can generally conclude from the patterns of carbonate concentration given in Figure 5 that multiple processes, including productivity and dissolution, are important for determining the space-time variability of equatorial Pacific Ocean carbonate sedimentation and preservation. The variations of these multiple processes are best quantified using EOF analysis with one time series and one spatial map describing each independent mode of variation. An EOF analysis of the records for 0 to $6 \mathrm{Ma}$ for Sites 846 through 853 resolves two modes of variability that together explain $76 \%$ of the total variance. The spatial patterns of these two modes are presented in map form in Figure 8 , and the amplitude time series of the two spatial modes are given in Figure 9. The influence of dissolution relative to carbonate productivity when determining these patterns is discussed in the section following presentation of the results.

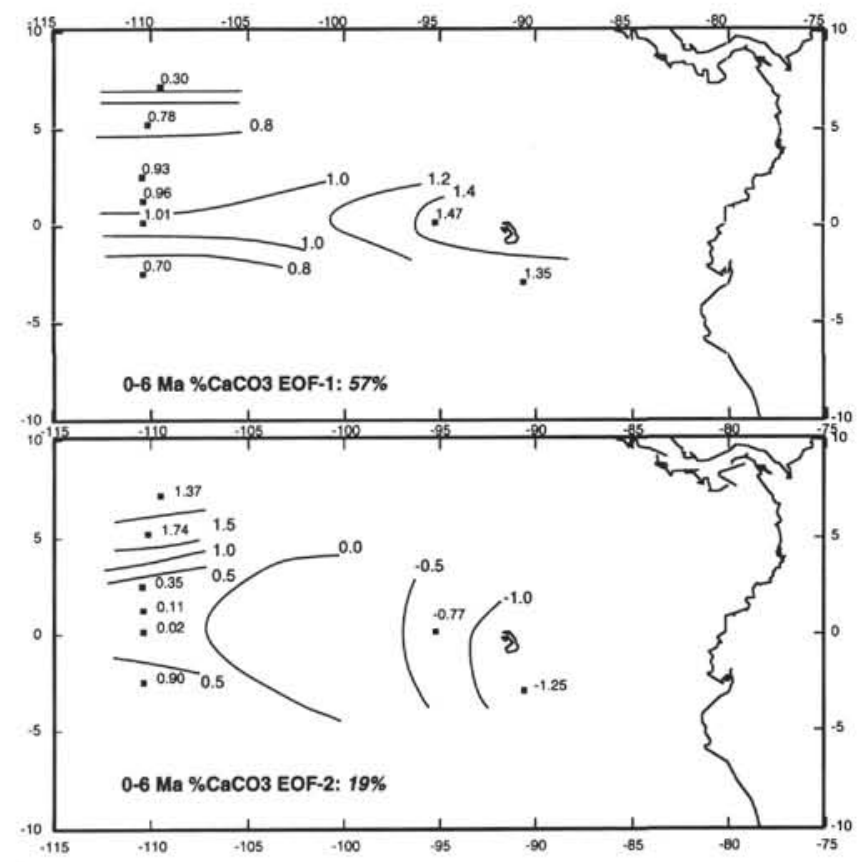

Figure 8. EOF-1 (top) and EOF-2 (bottom) of $\% \mathrm{CaCO}_{3}, 0$ to $6 \mathrm{Ma}$. Values contoured are the loadings for each EOF (elements of the eigenvector), normalized by the length of the eigenvector so that the average loading is 1.0. 

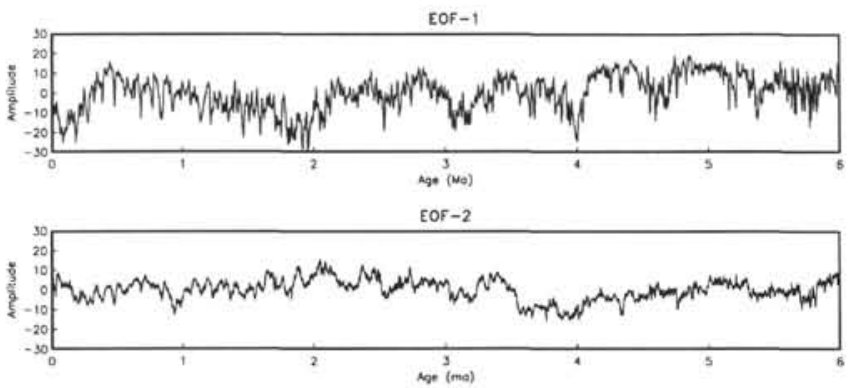

Figure 9. Amplitude time series of EOF-1 (top) and EOF-2 (bottom) of 0 to $6 \mathrm{Ma}_{\%} \mathrm{CaCO}_{3}$

The first EOF for the 0- to 6- $\mathrm{Ma} \mathrm{CaCO}_{3}$ record accounts for $57 \%$ of the total variance. The spatial map of EOF-1 (Fig. 8, top) has highest loading at eastern transect Sites 846 and 847 . On the western transect, the highest loading is at Site 849 , with loadings decreasing to the north and south. This pattern suggests that the dominant mode of $\mathrm{CaCO}_{3}$ variability may be related to equatorial divergence.

The amplitude time series (Fig. 9,top) and power spectrum (Fig. 10) of EOF-1 indicate dominance by a combination of low frequency (200-250 k.y.) and higher-frequency Milankovitch band oscillations. Very high coherence is present between insolation at $65^{\circ} \mathrm{N}$ (Berger and Loutre, 1988) and EOF-1 at periods of 41,23, 19, and 17 k.y. (Fig. 10 and Table 5). $65^{\circ} \mathrm{N}$ insolation and EOF-1 are in phase where coherent, with the exception of the 100-k.y. period, where phase is near $-180^{\circ}$. The near-zero phase at the dominant insolation frequencies reflects the orbital calibration of the chronology.

The spatial map for EOF- 2 accounts for more than $19 \%$ of the total variance. The highest loadings are off-equator on the $110^{\circ} \mathrm{W}$ transect, at Sites 848, 852, and 853, and at eastern transect Sites 846 and 847, where loadings are of the opposite sign (Fig. 8, bottom). The western transect equatorial sites have minimum loading. Thus, EOF-2 appears to represent a mode of variability having both north-south and eastwest asymmetry.

The amplitude time series for EOF-2 (Fig. 9, bottom) indicates a distinct step in amplitude between 3 and $4 \mathrm{Ma}$, at approximately 3.6 $\mathrm{Ma}$. This change in the variability of EOF-2 might be related to changes in external boundary conditions that affect carbonate sedimentation, such as the closure of the Panamanian isthmus. Changes in the spatial mode of variability in EOF-2, described below, support such a change in EOF-2 during this time interval.

Variance in the amplitude time series of EOF-2 (Fig. 10) is dominated by low frequencies that are not coherent with insolation variations. Although significant $(0.80$ level $)$ coherence is present at some Milankovitch frequencies (Fig. 10; Table 5), at a 0.90 level, none of the frequencies in the EOF-2 time series are coherent with insolation. In the precession band where insolation and EOF-1 are also coherent, insolation and EOF- 2 have a phase close to $180^{\circ}\left(143 \pm 26^{\circ}\right.$ for $23 \mathrm{k} . \mathrm{y}$., and $170 \pm 21^{\circ}$ for 19 k.y.). This separation of Milankovitch band variability into two modes may imply that multiple processes are operating at the same frequencies.

\section{Evolution of $\mathrm{CaCO}_{3}$ Variability}

As discussed in the "Introduction" section (this chapter), large changes in both climatic and tectonic boundary conditions have occurred over the past $6 \mathrm{~m}$.y. In accord with previously documented changes, large changes in carbonate and bulk sedimentation rates occurred at all sites from 6 to $4.7 \mathrm{Ma}$ (Mayer, et al., 1992). It is not well understood how these changes have influenced the modes of variability in the equatorial Pacific $\mathrm{CaCO}_{3}$. Evolutive spectra of $\mathrm{CaCO}_{3}$ variability also suggest a transition near $1 \mathrm{Ma}$, which coincides with changes in global ice volume (Mayer et al., this volume).
Table 5. Results of cross-spectral analyses between $65^{\circ} \mathrm{N}$ insolation and $\mathrm{EOFs} 1$ and 2,0 to $6 \mathrm{Ma}, \% \mathrm{CaCO}_{3}$.

\begin{tabular}{cccccc}
\hline $\begin{array}{c}\text { Period } \\
\text { (k.y.) }\end{array}$ & Coh. $^{2}$ & $\begin{array}{c}\text { Phase } \\
\text { (degrees) }^{\mathrm{h}}\end{array}$ & $\begin{array}{l}\text { Period } \\
\text { (k.y.) }\end{array}$ & Coh. & $\begin{array}{c}\text { Phase } \\
\text { (degrees) }\end{array}$ \\
\hline $\begin{array}{c}\text { EOF-1 } \\
125\end{array}$ & 0.43 & $-176 \pm 28$ & $\begin{array}{c}\text { EOF-2 } \\
100\end{array}$ & 0.43 & $-1.37 \pm 29$ \\
41 & 0.86 & $9 \pm 9$ & 67 & 0.54 & $-51 \pm 22$ \\
36 & 0.81 & $-156 \pm 11$ & 23 & 0.47 & $143 \pm 26$ \\
23.8 & 0.92 & $-10 \pm 6$ & 19 & 0.45 & $-178 \pm 27$ \\
22.2 & 0.93 & $-5 \pm 6$ & 17 & 0.95 & $96 \pm 5$ \\
19 & 0.88 & $-5 \pm 8$ & 12 & 0.51 & $-30 \pm 24$ \\
17 & 0.96 & $-44 \pm 4$ & 11 & 0.62 & $-36 \pm 18$ \\
15 & 0.60 & $64 \pm 19$ & & & \\
14 & 0.46 & $27 \pm 26$ & & & \\
12 & 0.52 & $22 \pm 23$ & & & \\
10 & 0.75 & $0 \pm 13$ & & & \\
& & & & & \\
\hline
\end{tabular}

Coh. $=$ Coherence for periods significant at 0.80 level.

b Positive phase indicates that insolation leads the EOF.
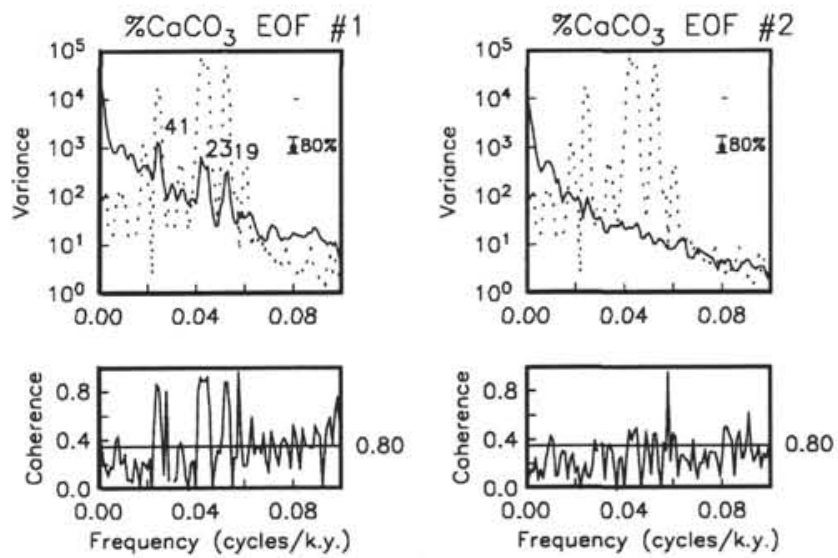

Figure 10. Power and coherence spectra for EOF-1 (left) and EOF-2 (right), respectively, and $65^{\circ} \mathrm{N}$ insolation (Berger and Loutre, 1988), for the 0 to 6 Ma amplitude time series given in Figure 9. Solid line indicates the EOF power spectra; dotted line is the insolation power spectrum. The $80 \%$ confidence limits and bandwidth on the spectra are illustrated in the top panel. Horizontal line in the bottom panel indicates the 0.80 significance level for coherence.

To account for these changes and also to determine the modes of variability that characterize carbonate sedimentation, separate EOF analyses were performed on successive 1-m.y. time intervals.

The spatial maps of the two dominant EOFs for each time slice are shown in Figure 11. The Leg 138 sites in each spatial map have been backtracked and are located at approximate paleolatitudes, according to the rotation of Cox and Engebretson (1985; note that the presentday geography is superimposed on the backtracked site locations in Fig. 11). In each time interval, two modes dominate. The total amount of variance explained by these two modes is consistent, with EOF-1 representing from $44 \%$ to $67 \%$, and EOF- 2 representing from $15 \%$ to $32 \%$ of the overall variance. In only one time interval, from 5 to $6 \mathrm{Ma}$, is the variance in the third EOF (not shown) greater than $10 \%$.

With the exception of Site 852, which has a high loading from 3 to $4 \mathrm{Ma}$ and from 5 to $6 \mathrm{Ma}$, the spatial pattern of EOF-1 in each time slice shows coupling to the equator (Figs. $11 \mathrm{~A}-11 \mathrm{~F}$ ). As with the results from 0 to $6 \mathrm{Ma}$, the spatial pattern of EOF-1 in each interval suggests an influence of surface ocean processes on variations in $\mathrm{CaCO}_{3}$ concentration. The EOF loadings are shown as a function of latitude across the $110^{\circ} \mathrm{W}$ transect in Fig. 12A. High loadings in EOF-1 occur at the equator, with a secondary peak at $4^{\circ}$ to $5^{\circ} \mathrm{N}$ (Site 852). The relationship between modern water depth and the EOF 

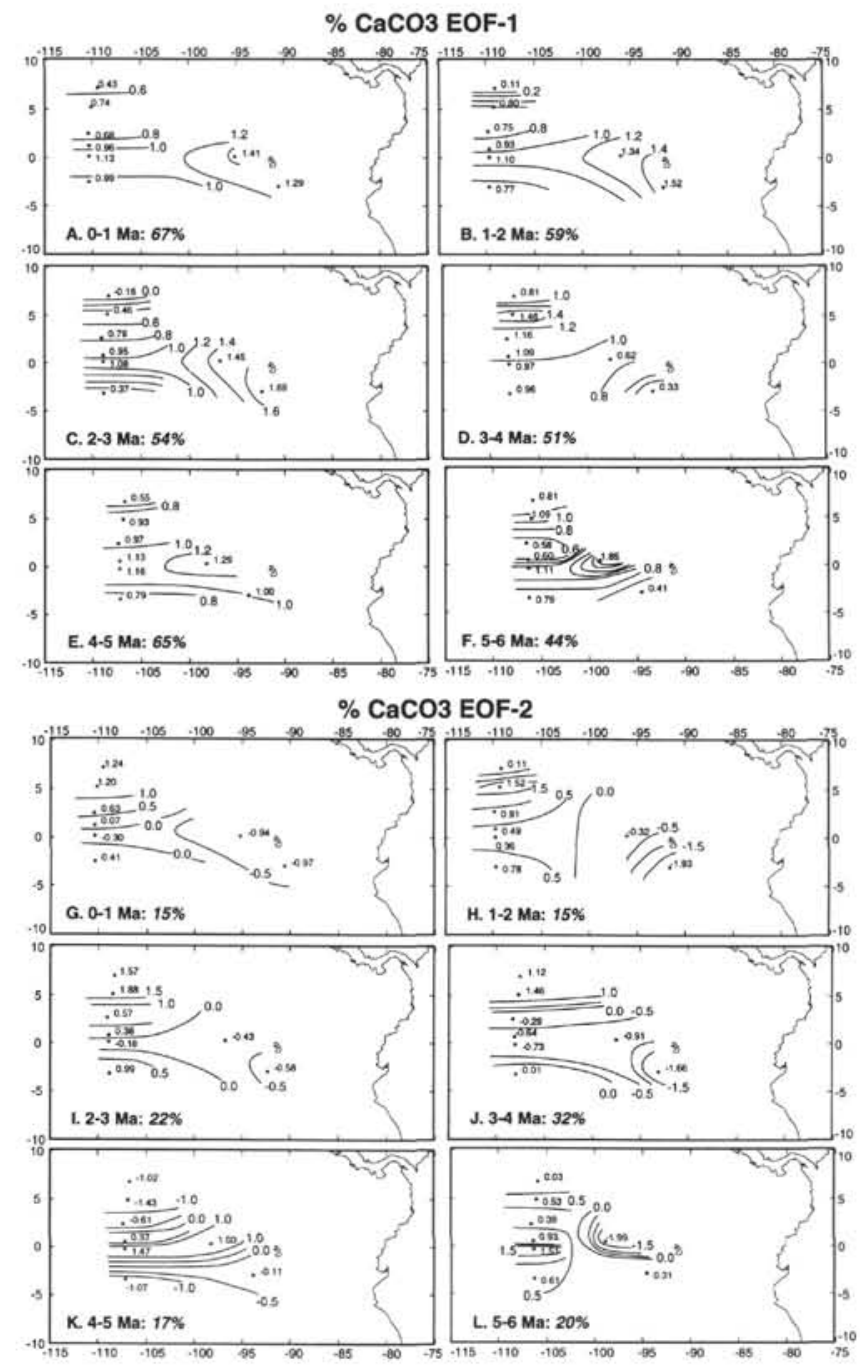

Figure 11. A-F. EOF-1 of $\% \mathrm{CaCO}_{3}$ in 1-m.y, time slices, 0 to $6 \mathrm{Ma}$. G-L. EOF-2 of $\% \mathrm{CaCO}_{3}$ in 1-m.y. time slices. Site locations are at approximate paleolatitudes and paleolongitudes for each time slice. South America is located at the modern location.

loadings for each time slice is shown in Figure 12B. Although relationships are difficult to resolve because of close depth spacing of Sites 848,849 , and 852 , the loadings of EOF-1 do not show any overall correlation with depth.

The spatial pattern of EOF-2 has similar features in the time intervals from 0 to $1 \mathrm{Ma}$ through 3 to $4 \mathrm{Ma}$ (Figs. $11 \mathrm{G}-11 \mathrm{~L}$ ). Like the analysis for the period from 0 to $6 \mathrm{Ma}$, a pattern of out-of-phase east-west loadings is present, with eastern transect Sites 846 and 847 having loadings opposite in sign of the western transect loadings. On the western transect, equatorial Sites 849 and 850 have minimum loadings, while the off-equatorial sites have higher loadings. The highest positive loadings are at Site 852 , and highest negative loadings are at Site 846. Prior to 3 to $4 \mathrm{Ma}$, a different spatial pattern is present. The interval from 4 to $5 \mathrm{Ma}$, while showing a high loading at Site 852 , does not display the east-west asymmetry of the interval from 0 to $4 \mathrm{Ma}$. The spatial pattern of EOF- 2 from 5 to 6 Ma does not appear to have any similarities with the later time intervals. These features also are evident in Figures 12C and 12D, which show latitudinal and depth gradients for EOF-2. Figure 12D indicates a correlation between water depth and EOF-2 loadings, particularly between the eastern and western transects.

The change in the spatial pattern of EOF- 2 between 3 to $4 \mathrm{Ma}$ and 4 to 5 Ma may be related to changes associated with closure of the
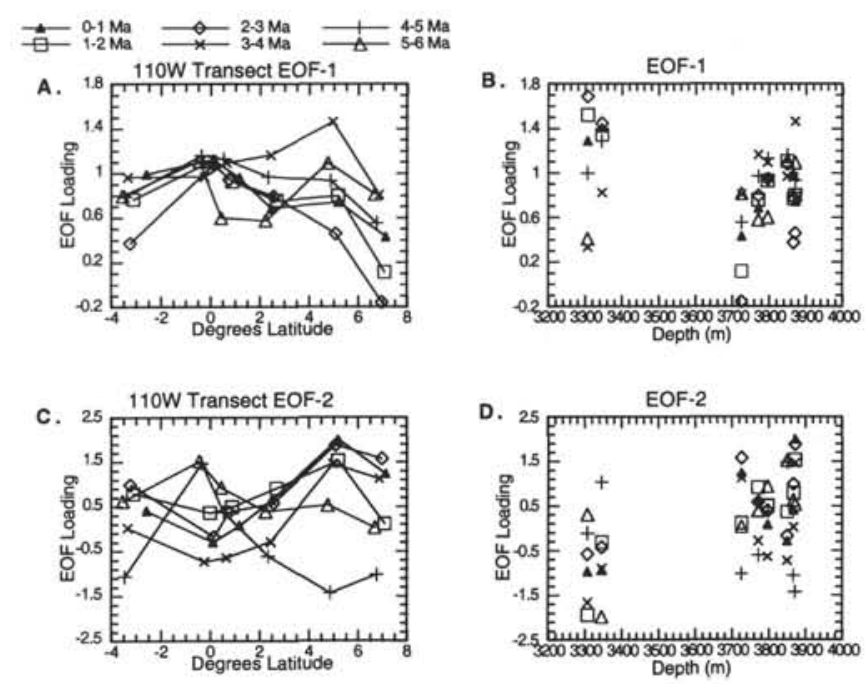

Figure 12. A. $\% \mathrm{CaCO}_{3}$ 1.m.y. time slice EOF-1 loadings (y-axis) as a function of latitude ( $x$-axis) on the $110^{\circ} \mathrm{W}$ transect. B. EOF-1 loadings for time slice as a function of present water depth. C. EOF-2 loadings on the $110^{\circ} \mathrm{W}$ transect. D. EOF-2 loadings as a function of water depth.

Panamanian isthmus. This interpretation is highly dependent on the EOF loading at Site 847 and, thus, should be taken with caution. However, Figure 12C also indicates a different spatial pattern of EOF- 2 on the $110^{\circ} \mathrm{W}$ transect from 3 to $4 \mathrm{Ma}$ and 5 to $6 \mathrm{Ma}$ than in later periods. This difference is not dependent on Site 847. In addition, the amplitude time series of EOF-2 for the entire 0- to 6-Ma interval (Fig. 9) suggests a change in character between 3 and $5 \mathrm{Ma}$. Together, these patterns suggest that EOF-2 indicates a response of carbonate sedimentation to a change in oceanographic boundary conditions between 3 to $4 \mathrm{Ma}$ and 4 to $5 \mathrm{Ma}$.

The amplitude time series for EOF-1 and EOF-2 for each 1-m.y. time slice are given in Figures 13A through 13F. In general, the EOF-1 time series have more distinct concentrations of variance than that in the EOF-2 time series, and the EOF-2 time series have little orbital-band variability (Fig. 14). Coherence with insolation is extremely high for EOF-1 in each time interval (Figs. 14A-14F and Table 6 ) and is significant at a 0.80 level (coherence $=0.67$ ) as well as a 0.90 level (coherence $=0.88$ ). These strong linear relationships indicate that the dominant variability in the $\mathrm{CaCO}_{3}$ record over the past 6 m.y. includes Milankovitch variability. EOF- 2 has high coherence with precession band variations only from 3 to $4 \mathrm{Ma}$ and 5 to 6 Ma (Figs. 14G-14L). As with the previous EOF analysis of the 0 to 6 $\mathrm{Ma}$ interval, near-zero phase between $65^{\circ} \mathrm{N}$ insolation and EOF-1 reflects the constraint imposed by the orbital calibration of the time scale. Where coherence between EOF-2 and insolation is significant, the phase indicates that two processes are operating at the same Milankovitch frequencies, each of which has a different relationship to insolation. Most of the coherence observed between EOF-2 and insolation is not coherent at a 0.90 level, and occurs at "non-Milankovitch" frequencies. Thus, most of the variability in EOF-2 is not linearly related to insolation.

\section{Patterns in Carbonate Mass Accumulation Rates}

The role of noncarbonate dilution must be considered before one makes any conclusions with respect to the role of carbonate production relative to carbonate dissolution in driving the spatial patterns of $\mathrm{CaCO}_{3}$. Is the carbonate concentration record reflecting dilution by noncarbonate sedimentary components (primarily biogenic opal) more than processes related to carbonate sedimentation? Analysis of carbonate MAR time series can address this issue. If spatial patterns similar to the carbonate concentration EOFs are present, then dilution 
$\% \mathrm{CaCO}_{3} \mathrm{EOF} 1$

A.

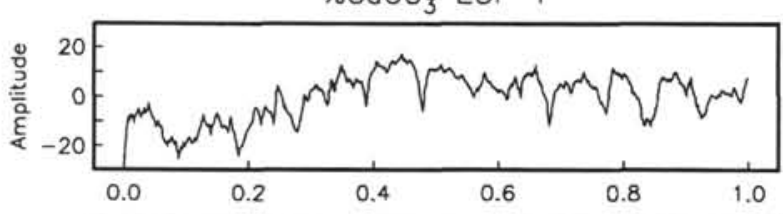

B.

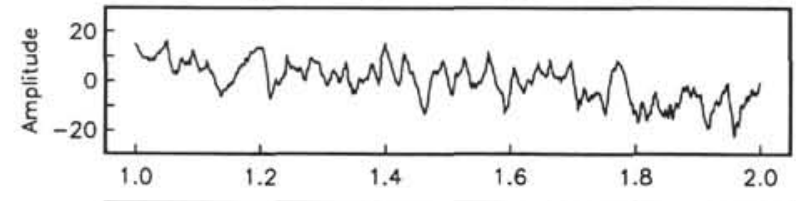

c.

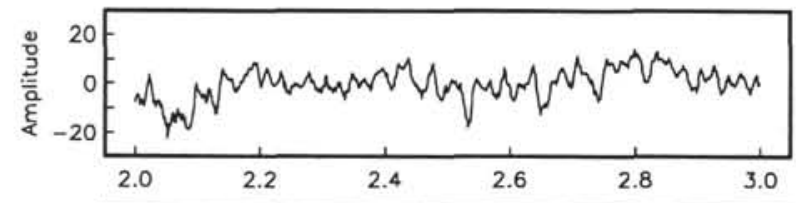

D.

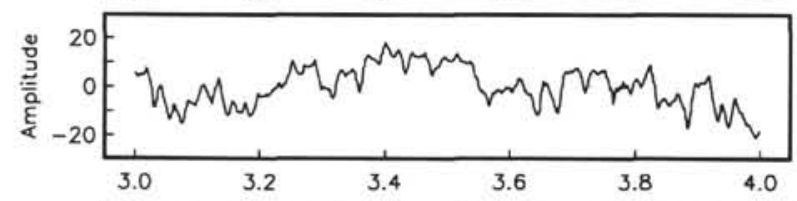

E.
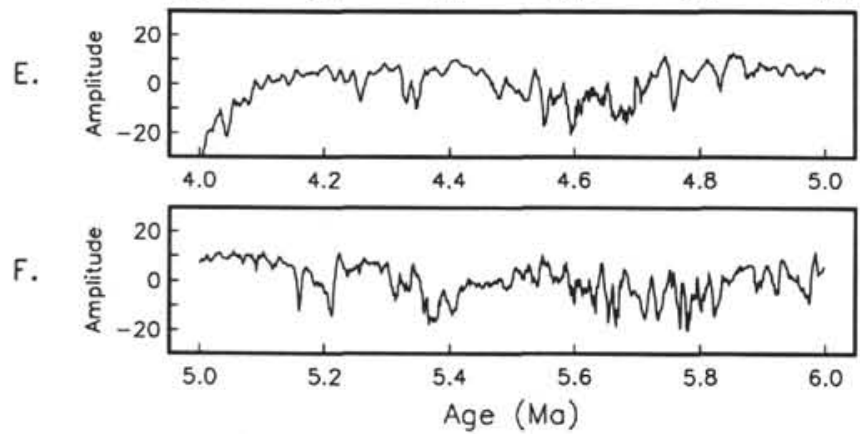

$\% \mathrm{CaCO}_{3}$ EOF 2
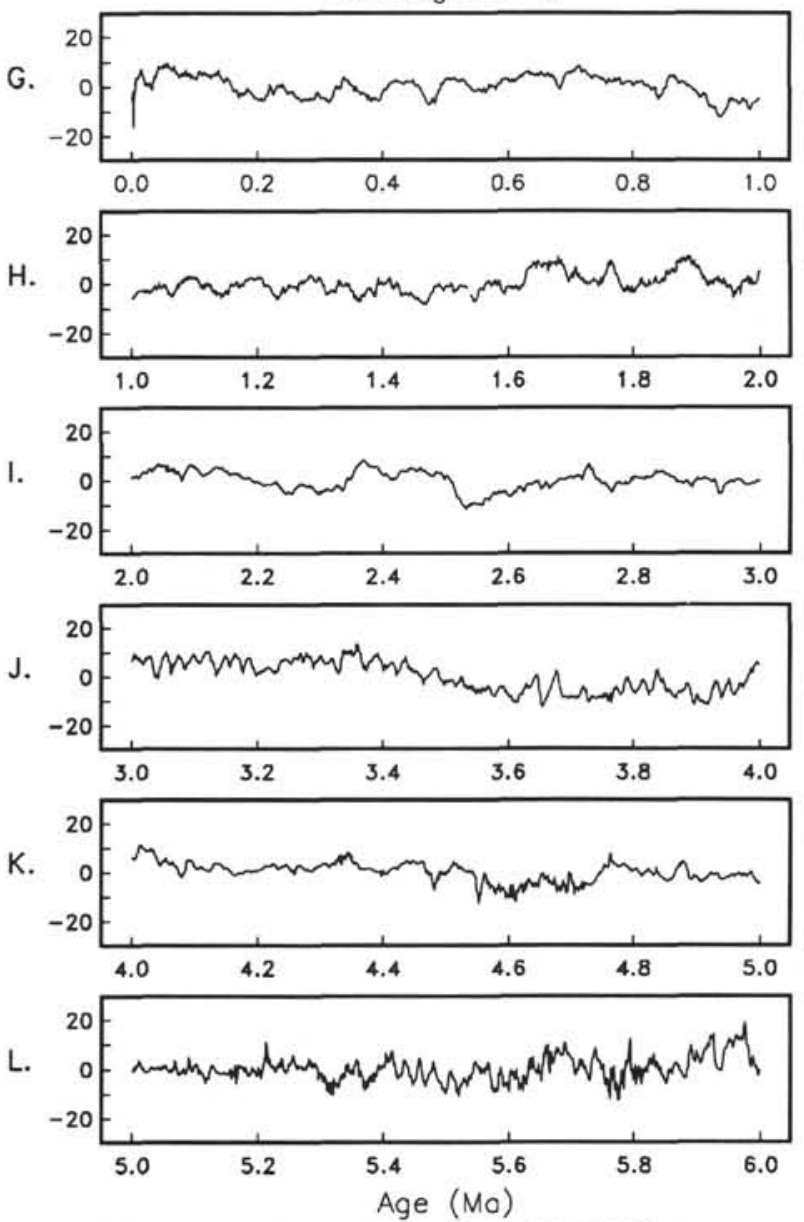

Figure 13. A-F. Amplitude time series of 1-m.y. time slice $\% \mathrm{CaCO}_{3}$ EOF-1. G-L. Amplitude time series of 1-m.y. time slice $\% \mathrm{CaCO}_{3} \mathrm{EOF}-2$.

can be ruled out as the primary cause of the spatial variability in carbonate. An EOF analysis was done using the 0- to 6-Ma carbonate MAR time series (Fig. 7). As with $\mathrm{CaCO}_{3}$ concentration data, two EOFs explain $77 \%$ of the total variance in the time series for Sites 846 through 853. Spatial maps for EOF-1, which explains $65 \%$ of the total variance, and EOF-2, which explains $12 \%$ of the total variance, are given in Figure 15.

The carbonate MAR EOFs confirm the inferences drawn from the $\mathrm{CaCO}_{3}$ concentration results. A strong coupling to the equator is present in the spatial pattern of EOF-1, indicating the domination of the influence of surface water on carbonate sedimentation. The pattern is similar to EOF-1 of carbonate concentration (Fig. 8). While in some short intervals of Sites 846 through 853 low carbonate concentration is indeed a result of dilution by noncarbonate, for example, time intervals dominated by monospecific diatom ooze (Kemp and Baldauf, this volume), these intervals are not representative of the dominant variability over all records, and the EOF analyses represent the time-integrated modes of variability. Thus, although dilution may play some role in influencing $\mathrm{CaCO}_{3}$ variability, it is not the dominant process. The second EOF for the carbonate MARs displays strong east-west asymmetry. The spatial pattern is not similar to the second EOF for the $\mathrm{CaCO}_{3}$ concentration, suggesting that they are reflecting different oceanographic processes.

The loadings of EOF-1 across the $110^{\circ} \mathrm{W}$ transect (Fig. 16A) highlights the strong coupling to the equator. These loadings parallel variations in sediment thickness (and thus sedimentation rates). However, a normalized sedimentation rate comparison between sites has indicated that attenuation of records at the lower sedimentation rate sites $(848,852$, and 853$)$ is not simply a function of sedimentation rate (Pisias et al., 1992). Thus, the equatorial pattern displayed by EOF-1 cannot be entirely a function of sedimentation rate. The latitudinal transect for EOF-2 of carbonate MAR (Fig. 16C) does not indicate a clear relationship. Neither EOF-1 nor EOF-2 of carbonate MAR appears to have a correlation with water depth (Figs. 16B and 16D).

The frequency resolution of MAR time series is limited by the resolution of the sedimentation rates of the records. If the low sedimentation rate resolution at Site $853(\sim 200$ k.y.) is taken as the limiting factor, spectral analyses are not appropriate for the carbonate MAR EOFs. Even so, cross-spectral analyses among the $\mathrm{CaCO}_{3}$ MAR EOFs (not shown) indicated high coherence between the EOF-1 amplitude time series and $65^{\circ} \mathrm{N}$ insolation. Comparisons between EOF-1 and EOF-2, respectively, of the $\mathrm{CaCO}_{3}$ concentration and MAR records indicates that EOF- 1 of carbonate concentration and carbonate MAR are highly positively correlated. In the frequency domain, the two EOFs are highly coherent with one another (often greater than 0.95 ) at a broad range of frequencies. From these results, it is reasonable to conclude that the dominant mode of variability in carbonate concentration and carbonate MAR reflect the same fundamental oceanographic process and that over the past 6 m.y., the $\mathrm{CaCO}_{3}$ concentration spatial pattern is not driven dominantly by dilution.

EOF-2 of $\mathrm{CaCO}_{3}$ concentration and MAR appear to reflect different processes. The two modes of variability are not highly correlated from 0 to $6 \mathrm{Ma}$. The spatial maps (Figs. 8 and 15) also differ. While EOF-2 of $\mathrm{CaCO}_{3}$ concentration may be influenced by dissolution processes, EOF-2 of carbonate MAR indicates a process operating in 

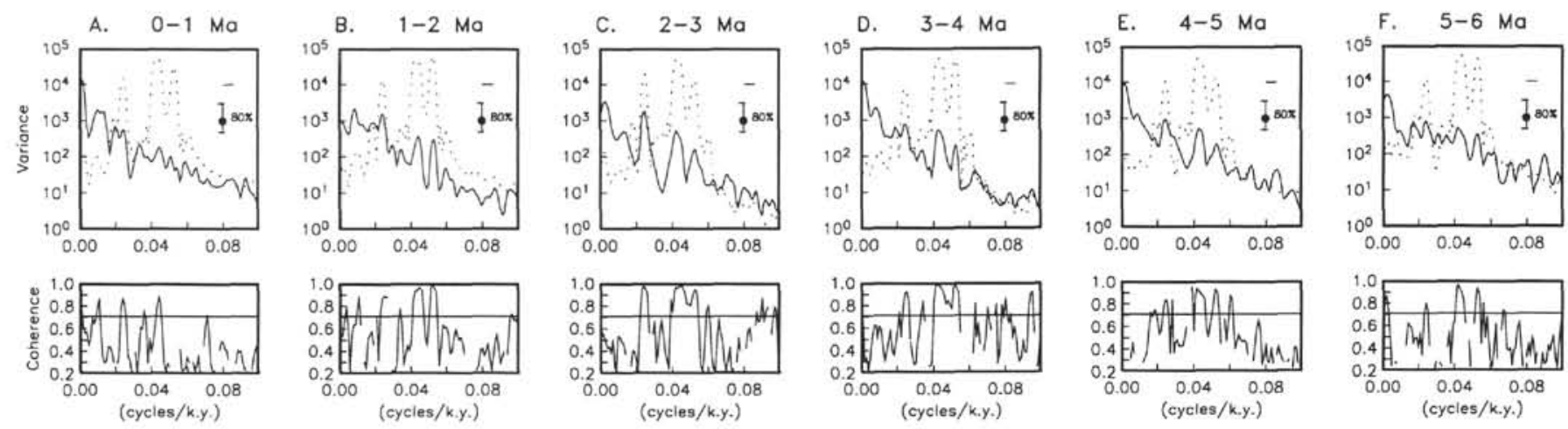

G. $0-1 \mathrm{Ma}$
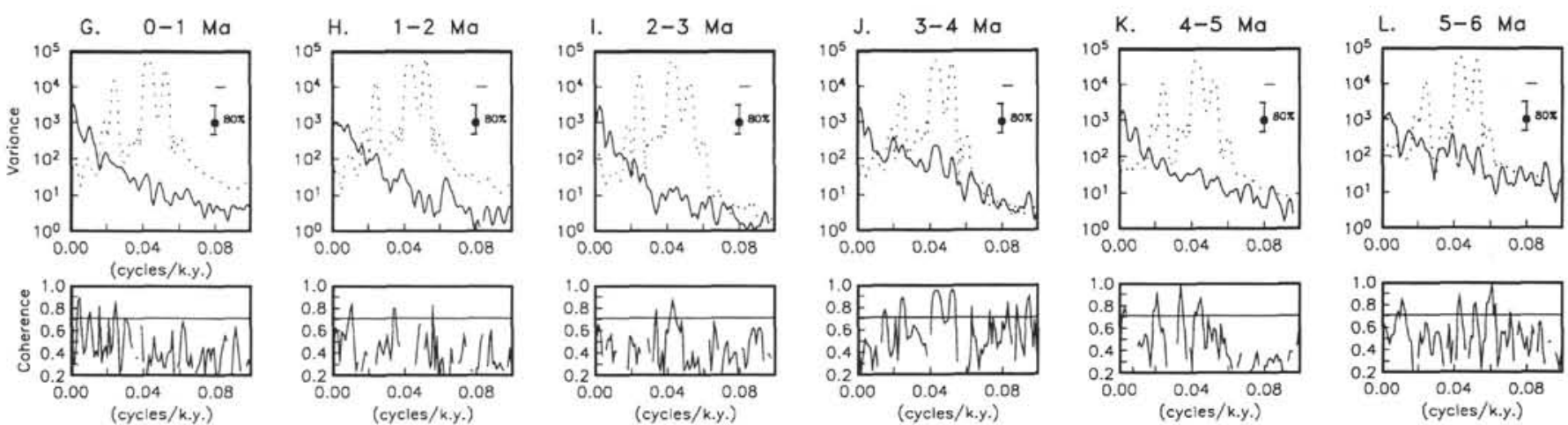

Figure 14. A-F. Power and coherence spectra for EOF-1 and $65^{\circ} \mathrm{N}$ insolation, for the 1-m.y. time slice amplitude time series given in Figure 13. G-L. Power and coherence spectra for EOF- 2 and $65^{\circ} \mathrm{N}$ insolation for the amplitude time series given in Figure 13. Symbols are as described in the caption for Figure 10 .

the carbonate system that is independent of both the dominant modes of variability (EOF-1) and EOF-2 of carbonate concentration.

\section{Frequency Domain Analyses}

The observation that much of the variability represented in EOF-1 is strongly coherent with solar insolation raises yet another question: does each frequency band have the same spatial structure? The analy-

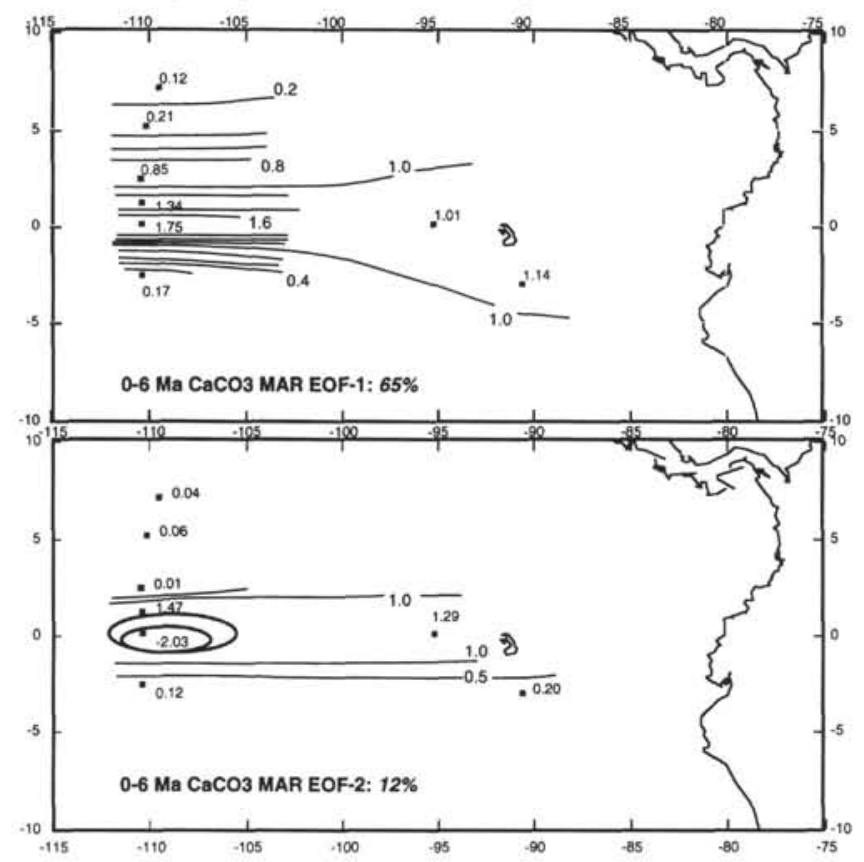

Figure 15. EOF-1 (top) and EOF-2 (bottom) of the $\mathrm{CaCO}_{3}$ MAR time series given in Figure 7. ses presented above consider all frequencies of each time series together, to determine empirically the independent modes of variability. As demonstrated by Imbrie et al. (1993), the processes controlling climatic variations operate differently in the primary Milankovitch frequency bands. It is physically meaningful to examine three of the dominant frequency bands of the carbonate time series separately. For instance, the 23- to 19-k.y. band associated with precession variations may have a different spatial representation than the 41-k.y. band associated with orbital obliquity. In addition, at frequencies lower than 41 k.y., where little variance is present in insolation, most of the variance in carbonate variability is concentrated.
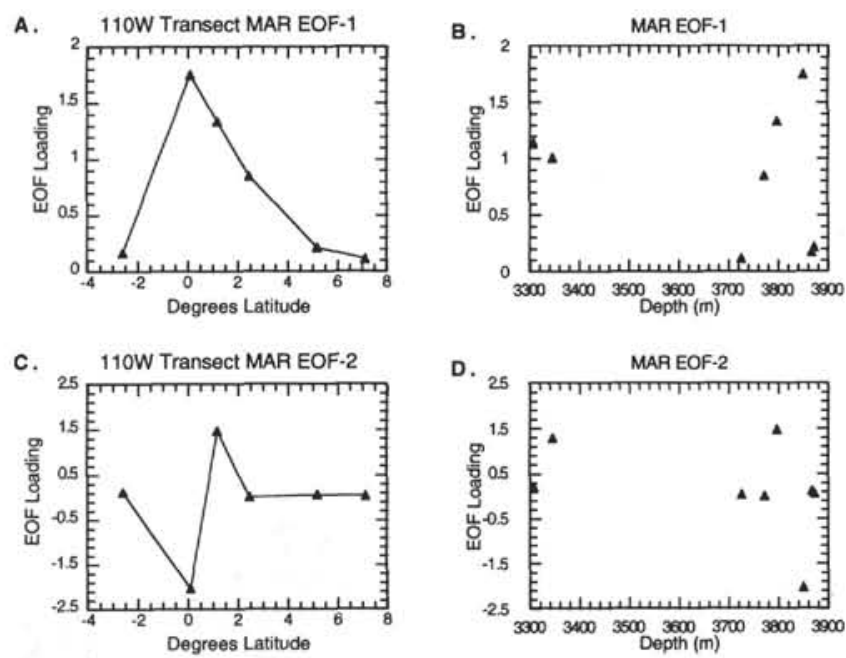

Figure 16. A. EOF-1 loadings of the $\mathrm{CaCO}_{3} \mathrm{MAR}$ EOFs on the $110^{\circ} \mathrm{W}$ transect. B. EOF-I loadings as a function of present water depth. C. EOF-2 loadings on the $110^{*} \mathrm{~W}$ transect. D. EOF-2 loadings as a function of water depth. 
Table 6. Summary of cross-spectral results between $65^{\circ} \mathrm{N}$ insolation and $\mathrm{CaCO}_{3} \mathrm{EOFs} 1$ and 2 .

\begin{tabular}{|c|c|c|c|c|c|}
\hline $\begin{array}{c}\text { Period } \\
(\text { k.y.) }\end{array}$ & Coh. & $\begin{array}{c}\text { Phase } \\
\text { (degrees) }\end{array}$ & $\begin{array}{l}\text { Period } \\
\text { (k.y.) }\end{array}$ & Coh. & Phase \\
\hline \multicolumn{6}{|l|}{$0-1 \mathrm{Ma}$} \\
\hline EOF-1 & & & EOF-2 & & \\
\hline 100 & 0.86 & $-101 \pm 18$ & 200 & 0.89 & $-179 \pm 16$ \\
\hline 41 & 0.87 & $7 \pm 17$ & 91 & 0.76 & $-99 \pm 25$ \\
\hline 28 & 0.76 & $-179 \pm 25$ & 63 & 0.82 & $9 \pm 21$ \\
\hline 23 & 0.88 & $-20 \pm 16$ & 40 & 0.85 & $-29 \pm 19$ \\
\hline 14 & 0.71 & $54 \pm 29$ & & & \\
\hline \multicolumn{6}{|l|}{$\mathrm{I}-2 \mathrm{Ma}$} \\
\hline EOF-1 & & & EOF-2 & & \\
\hline 250 & 0.79 & $102 \pm 23$ & 91 & 0.83 & $-107 \pm 20$ \\
\hline 91 & 0.88 & $-109 \pm 16$ & 29 & 0.80 & $130 \pm 23$ \\
\hline 40 & 0.89 & $4 \pm 16$ & 18 & 0.83 & $48 \pm 20$ \\
\hline 29 & 0.77 & $4 \pm 25$ & & & \\
\hline 23 & 0.97 & $-14 \pm 8$ & & & \\
\hline 19 & 0.98 & $-5 \pm 6$ & & & \\
\hline 10 & 0.73 & $-26 \pm 27$ & & & \\
\hline \multicolumn{6}{|l|}{$2-3 \mathrm{Ma}$} \\
\hline EOF-1 & & & EOF-2 & & \\
\hline 41 & 0.97 & $-13 \pm 8$ & 29 & 0.79 & $-159 \pm 23$ \\
\hline 24 & 0.97 & $-14 \pm 8$ & 23 & 0.87 & $15 \pm 18$ \\
\hline 22 & 0.98 & $-2 \pm 6$ & & & \\
\hline 19 & 0.94 & $2 \pm 11$ & & & \\
\hline 17 & 0.80 & $10 \pm 22$ & & & \\
\hline 11 & 0.87 & $99 \pm 17$ & & & \\
\hline \multicolumn{6}{|l|}{$3-4 \mathrm{Ma}$} \\
\hline EOF-1 & & & EOF-2 & & \\
\hline 41 & 0.92 & $47 \pm 13$ & 67 & 0.78 & $36 \pm 24$ \\
\hline 30 & 0.83 & $-3 \pm 20$ & 41 & 0.88 & $-114 \pm 16$ \\
\hline 23 & 0.98 & $-9 \pm 6$ & 23 & 0.95 & $169 \pm 10$ \\
\hline 19 & 0.98 & $-14 \pm 7$ & 19 & 0.96 & $175 \pm 9$ \\
\hline 16 & 0.82 & $58 \pm 21$ & 16 & 0.80 & $-125 \pm 22$ \\
\hline 14 & 0.77 & $104 \pm 25$ & 12 & 0.85 & $-104 \pm 19$ \\
\hline 12 & 0.87 & $37 \pm 18$ & 10 & 0.90 & $-124 \pm 15$ \\
\hline 10 & 0.92 & $60 \pm 13$ & & & \\
\hline \multicolumn{6}{|l|}{$4-5 \mathrm{Ma}$} \\
\hline EOF-1 & & & $\mathrm{EOF}-2$ & & \\
\hline 53 & 0.75 & $-63 \pm 26$ & 333 & 0.78 & $-170 \pm 24$ \\
\hline 41 & 0.84 & $-18 \pm 20$ & 48 & 0.91 & $108 \pm 14$ \\
\hline 36 & 0.84 & $138 \pm 20$ & 29 & 0.98 & $6 \pm 7$ \\
\hline 23 & 0.94 & $-2 \pm 12$ & 22 & 0.86 & $-14 \pm 27$ \\
\hline 19 & 0.93 & $-2 \pm 13$ & & & \\
\hline 17 & 0.87 & $57 \pm 17$ & & & \\
\hline \multicolumn{6}{|l|}{$5-6 \mathrm{Ma}$} \\
\hline EOF-1 & & & EOF-2 & & \\
\hline 333 & 0.86 & $-80 \pm 18$ & 91 & 0.85 & $-94 \pm 19$ \\
\hline 41 & 0.79 & $-20 \pm 23$ & 23 & 0.88 & $34 \pm 16$ \\
\hline 23 & 0.96 & $-23 \pm 9$ & 19 & 0.82 & $22 \pm 21$ \\
\hline 19 & 0.93 & $-1 \pm 12$ & 16 & 0.98 & $168 \pm 6$ \\
\hline 15 & 0.74 & $28 \pm 27$ & & & \\
\hline
\end{tabular}

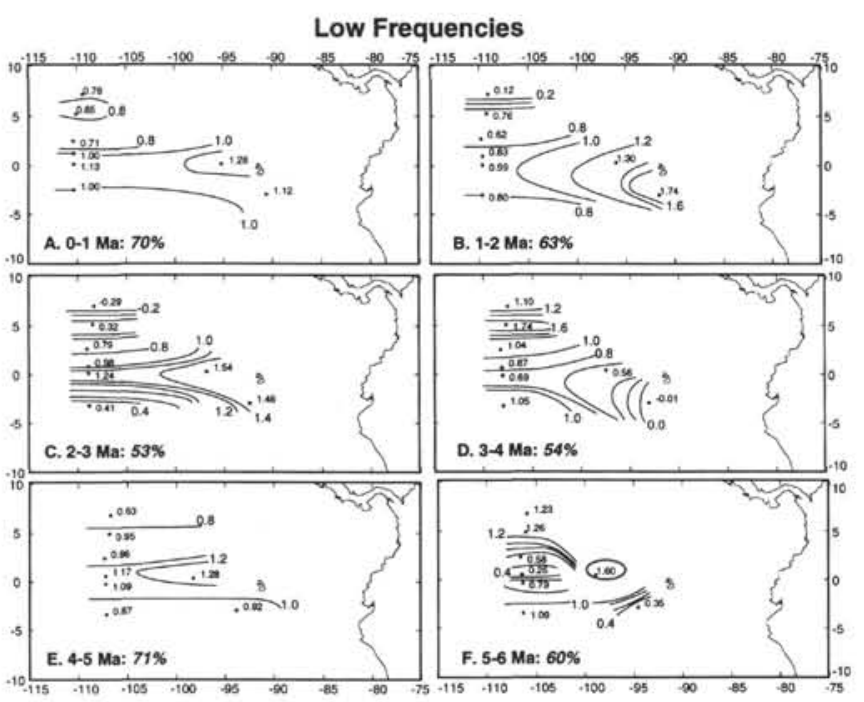

Figure 17. A-F. EOF-1 of the low-pass filtered $\% \mathrm{CaCO}_{3}$ times series in 1m.y. time slices, 0 to $6 \mathrm{Ma}$.
The $\mathrm{CaCO}_{3}$ concentration time series from Sites 846 through 853 were reanalyzed with this objective in mind. Each record was lowand band-pass filtered to isolate three groups of frequencies: frequencies lower than 45 cycles/k.y. ("low-pass"), frequencies from 45 to 35 cycles/k.y. ("tilt band"), and frequencies from 25 to 18 cycles/k.y. ("precession band"). The "low-pass" filter used a cosine taper having a half-amplitude at 0.016 cycles/k.y. (62.5 k.y.), which excluded energy at frequencies higher than 45 cycles/k.y. The tilt band filter was centered on 0.024 cycles/k.y. ( 41 k.y.), and had a bandwidth of 0.02 cycles/k.y. The precession band filter was centered at 0.048 cycles/k.y. (20.8 k.y.) and had a bandwidth of 0.03 cycles/k.y.

The results for EOF-1 of each of these analyses are shown in Figures 17 through 20 (EOF-2 of each frequency band represented substantially less of the total variance and is not discussed here). The spatial patterns of EOF-1 of the low-pass carbonate time series from 0 to $6 \mathrm{Ma}$ are similar to the unfiltered EOFs (Figs. 11 A-11F). This is expected as the dominant variability for the unfiltered EOF-1s were at low frequencies (Figs. 14A-14F). A high loading at Site 852 relative to Sites 851 and 853 is present from 3 to $4 \mathrm{Ma}$ and from 5 to $6 \mathrm{Ma}$ (Fig. 17). With the exception of 3 to $4 \mathrm{Ma}$ and 5 to $6 \mathrm{Ma}$, the maximum loading among the $110^{\circ} \mathrm{W}$ transect sites is at the equator (Fig. 18A). Loadings as a function of depth (Fig. 17B) are relatively constant and are not strongly correlated with depth.

The spatial patterns of EOF-1 in the tilt band have a spatial pattern with high loadings on the equator and at Site 852 at $\sim 6^{\circ}$ N. (Fig. 19). Comparison to the low-pass results indicate a higher coupling to the equator in this band than in the low-frequency band. Unlike the low-pass filtered records, the latitudinal transect (Fig. 18C) clearly
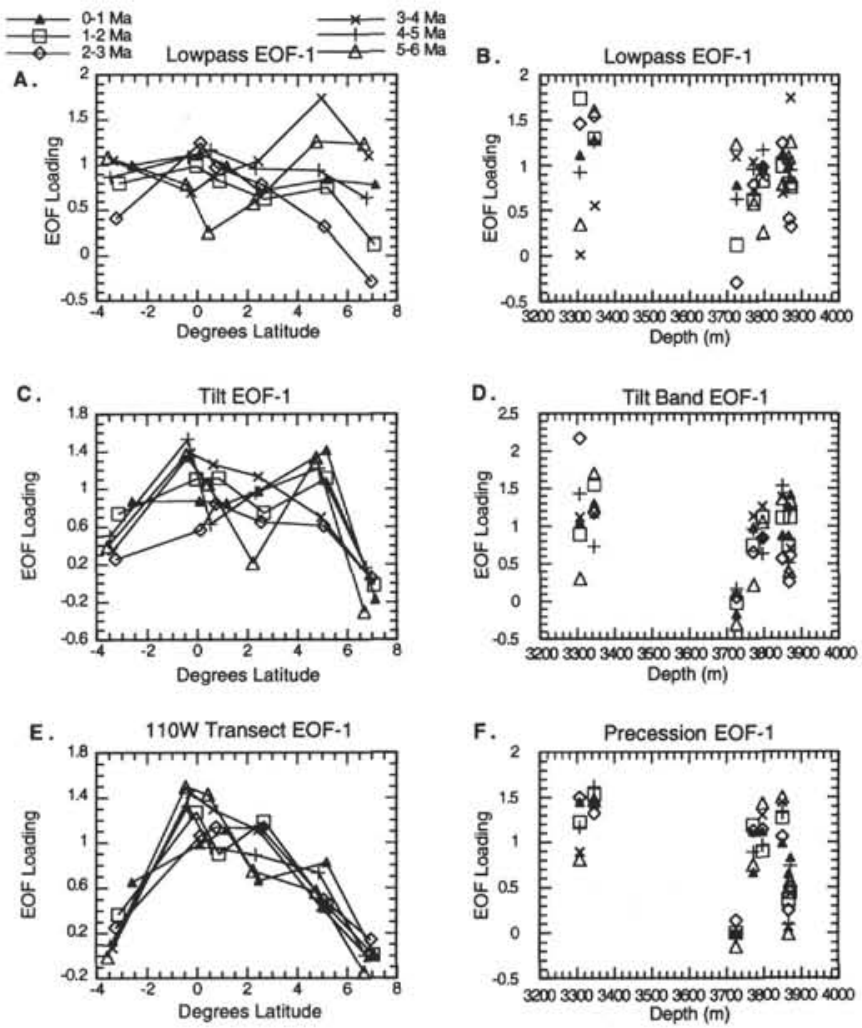

Figure 18. A. EOF-1 loadings of low-pass filtered $\% \mathrm{CaCO}_{3}$ time slices on the $110^{\circ} \mathrm{W}$ transect. B. Low-pass EOF-I loadings for each time slice as a function of present-day water depth. C. Tilt band $\% \mathrm{CaCO}_{3} \mathrm{EOF}-1$ loadings on the $110^{\circ} \mathrm{W}$ transect. D. Tilt band EOF-1 loadings as a function of water depth. E. Precession band $\% \mathrm{CaCO}_{3}$ EOF-1 loadings on the $110^{\circ} \mathrm{W}$ transect. f. Precession band EOF-1 loadings as a function of water depth. 


\section{Tilt Frequencies}

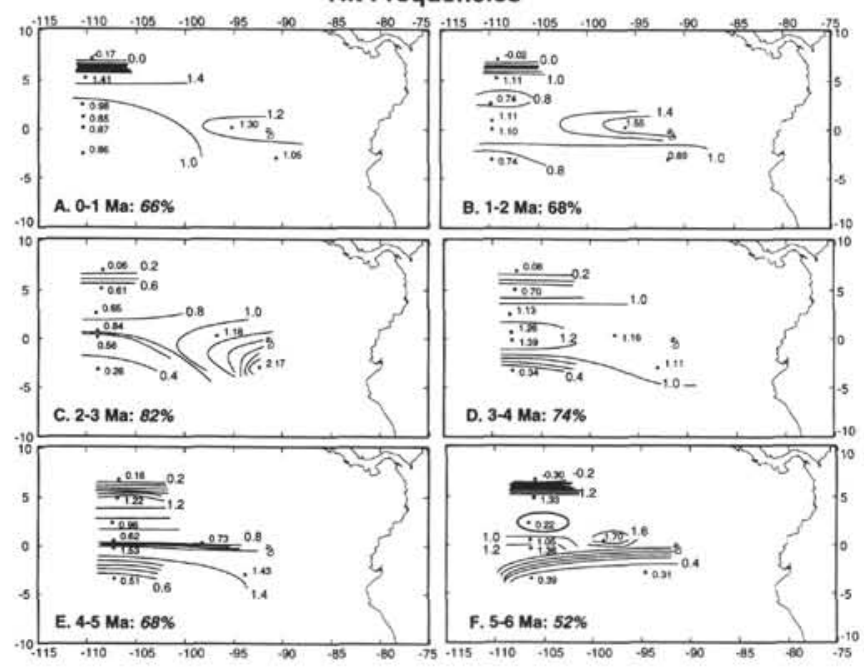

Figure 19. A-F. EOF-1 of the tilt band $\% \mathrm{CaCO}_{3}$ time series (see text) in 1m.y. time slices, 0 to $6 \mathrm{Ma}$.

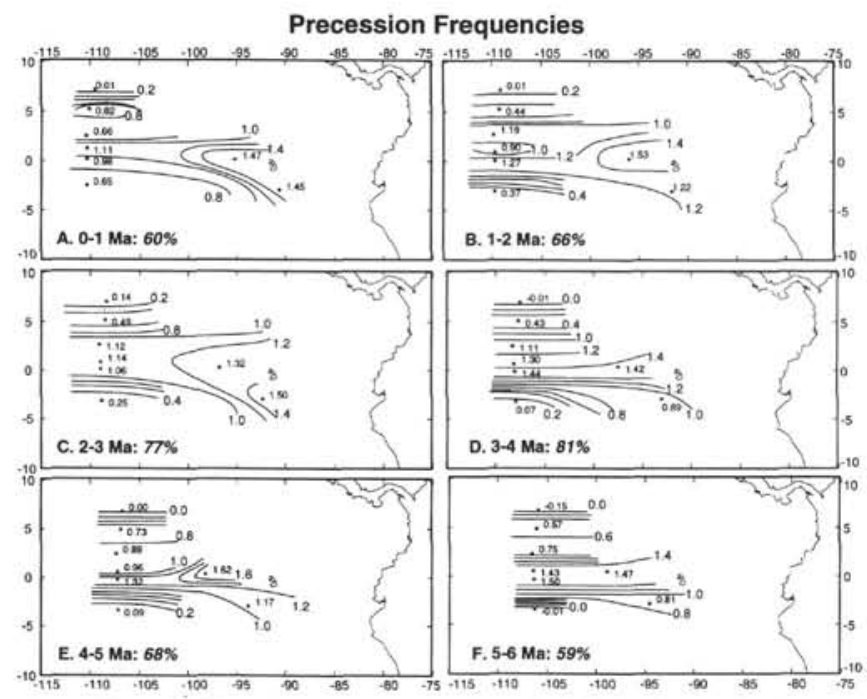

Figure 20. A-F. EOF-1 of the precession band $\% \mathrm{CaCO}_{3}$ time series (see text) in 1-m.y. time slices, 0 to $6 \mathrm{Ma}$.

resolves a two-peaked structure, with a peak at the equator and near $6^{\circ} \mathrm{N}$ (Site 852). No strong correlation between loadings and water depth is evident (Fig. 18D).

The precession band EOF-1 displays very high coupling to the equator and strong gradients away from the equator (Fig. 20). Variance at Site 852 is diminished relative to previous analyses. In every time interval in the tilt band, Site 852 relative to Sites 851 and 853 has a high loading, whereas in the precession band, the Site 852 loadings fall between the 851 and 853 loadings (Figs. 18C and 18E). Although error estimates for the EOF loadings are necessary to determine if these differences are significant, the consistency of this pattern in every time slice is striking. As with the lower frequencies, depth does not appear to correlate to the EOF loadings (Fig. I8F).

These frequency band analyses confirm that the mechanisms responsible for variability in carbonate concentration are operating on different time scales. The coupling to the equator evident in EOF-1 of the entire data set is strongest in the precession band, while variability at lower frequencies has the least coupling to the equator and to surface ocean processes. The high loadings at Site 852 in the unfiltered data set primarily reflect processes that are operating at lower frequencies. In the tilt band, variability appears to reflect surface oceanographic processes operating on the equator and near $6^{\circ} \mathrm{N}$, near the NECC boundary. Finally, variability in the precession band appears to be associated only with equatorial divergence and surface oceanographic processes.

\section{Carbonate and Ice Volume}

The relationships of the carbonate EOFs to ice volume over the past 4.5 m.y. were also examined. Previous studies (e.g., Farrell and Prell, 1991) suggested that the relationship between carbonate and ice volume seen over the late Pleistocene was not present during the Pliocene and early Pleistocene. A comparison between benthic $\delta^{18} \mathrm{O}$ and carbonate concentration EOFs may clarify this relationship. Comparisons were made between a spliced $849 / 846 \delta^{18} \mathrm{O}$ record (Mix et al., this volume; Shackleton et al., this volume) and $\mathrm{CaCO}_{3} \mathrm{EOFs} 1$ and 2 for each $1-$ m.y. time slice. (Comparisons having similar results were also made between $\delta^{18} \mathrm{O}$ and $\mathrm{CaCO}_{3} \mathrm{MAR}$ EOFs, but are not shown here.) Overall, $\delta^{18} \mathrm{O}$ and $\mathrm{CaCO}_{3}$ EOFs 1 and 2, respectively, are not highly correlated in any $1-\mathrm{m} . \mathrm{y}$. interval, having correlation coefficients no higher than 0.23 . Heavy isotopes (glacial) are correlated with positive EOF loadings (higher carbonate) for EOF-1, and with negative EOF loadings for EOF-2.

Although overall correlation is low, correlation is high in some frequency bands. Significant coherence between $\delta^{18} \mathrm{O}$ and the carbon-

Table 7. Summary of cross-spectral results at Site 846/849.

\begin{tabular}{|c|c|c|c|c|c|}
\hline $\begin{array}{c}\text { Period } \\
\text { (k.y.) }\end{array}$ & Coh. & $\begin{array}{l}\text { Phase } \\
\text { (degrees) }\end{array}$ & $\begin{array}{c}\text { Period } \\
\text { (k.y.) }\end{array}$ & Coh. & Phase \\
\hline \multicolumn{6}{|l|}{$0-1 \mathrm{Ma}$} \\
\hline 100 & 0.87 & $59 \pm 17$ & $\begin{array}{l}\text { EOr-2 } \\
91\end{array}$ & 0.96 & $61 \pm-9$ \\
\hline 71 & 0.87 & $9 \pm 17$ & 45 & 0.76 & $37 \pm-26$ \\
\hline 41 & 0.88 & $107 \pm 16$ & 40 & 0.89 & $84 \pm-16$ \\
\hline 23 & 0.83 & $149 \pm 20$ & 29 & 0.78 & $73 \pm-24$ \\
\hline 16 & 0.77 & $-133 \pm 24$ & 13 & 0.82 & $143 \pm-2 \mid$ \\
\hline \multicolumn{3}{|l|}{$\begin{array}{l}1-2 \mathrm{Ma} \\
\mathrm{EOF}-1\end{array}$} & \multicolumn{3}{|l|}{ EOF-2 } \\
\hline 111 & 0.91 & $57 \pm 14$ & 333 & 0.83 & $-15 \pm-20$ \\
\hline 77 & 0.86 & $54 \pm 18$ & 111 & 0.94 & $61 \pm-11$ \\
\hline 43 & 0.73 & $156 \pm 27$ & 83 & 0.76 & $44 \pm-25$ \\
\hline 29 & 0.80 & $0 \pm 22$ & 20 & 0.79 & $-77 \pm-23$ \\
\hline \multirow[t]{4}{*}{10} & 0.83 & $0 \pm 22$ & 17 & 0.91 & $129 \pm-28$ \\
\hline & & & 13 & 0.82 & $15 \pm-21$ \\
\hline & & & 12 & 0.89 & $10 \pm-16$ \\
\hline & & & 10 & 0.90 & $33 \pm-15$ \\
\hline
\end{tabular}

$\begin{array}{crr}\begin{array}{c}2-3 \mathrm{Ma} \\ \text { EOF-1 }\end{array} & & \\ 41 & 0.87 & 126 \pm 17 \\ 24 & 0.86 & 134 \pm 18 \\ 19 & 0.84 & -69 \pm 20 \\ 18 & 0.78 & 155 \pm 24 \\ 14 & 0.87 & -133 \pm 17\end{array}$

EOF-2

$\begin{array}{rcr}250 & .90 & 60 \pm-15 \\ 125 & 0.86 & 20 \pm-18 \\ 48 & 0.74 & 51 \pm-27 \\ 31 & 0.80 & 76 \pm-22 \\ 26 & 0.80 & -168 \pm-22 \\ 14 & 0.94 & 44 \pm-11 \\ 13 & 0.91 & -60 \pm-14\end{array}$

$\begin{array}{ccr}\begin{array}{c}3-4 \mathrm{Ma} \\ \text { EOF-1 }\end{array} & & \\ 53 & 0.90 & -161 \pm 15 \\ 40 & 0.91 & 135 \pm 14 \\ 2.3 & 0.93 & -152 \pm 12 \\ 19 & 0.78 & -122 \pm 24 \\ 14 & 0.84 & 169 \pm 20\end{array}$

EOF-2

$\begin{array}{rrr}50 & 0.96 & 20 \pm-9 \\ 40 & 0.93 & -27 \pm-12 \\ 31 & 0.78 & 9 \pm-24 \\ 23 & 0.90 & 22 \pm-15 \\ 20 & 0.84 & 69 \pm 19 \\ 14 & 0.77 & -47 \pm-24 \\ 11 & 0.92 & 72 \pm-13\end{array}$

\begin{tabular}{lrrrrr}
$4-4.6 \mathrm{Ma}$ & & \multicolumn{5}{c}{ EOF-2 } \\
EOF-1 & & & \\
33.3 & 0.90 & $-160 \pm 12$ & 13 & 0.77 & $-50 \pm-21$ \\
41 & 0.86 & $174 \pm 15$ & & & \\
18 & 0.75 & $158 \pm 22$ & & & \\
14 & 0.81 & $-57 \pm 18$ & & & \\
\hline
\end{tabular}

${ }^{a} \delta^{18} \mathrm{O}$ data from Shackelton et al. (this volume; Site 846) and Mix et al. (this volume; Site 849). 
A. $0-1 \mathrm{ma}$
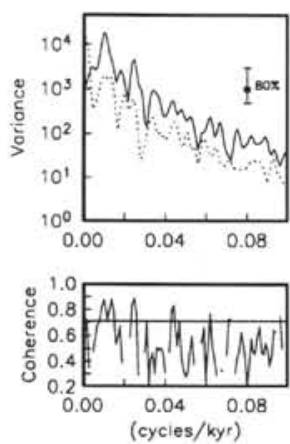

F. 0-1 mo
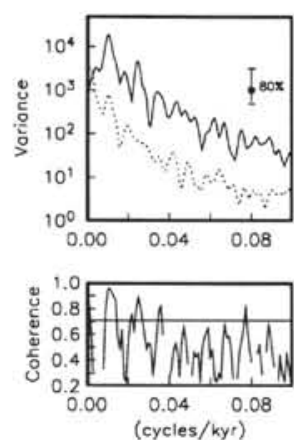

B. 1-2 ma
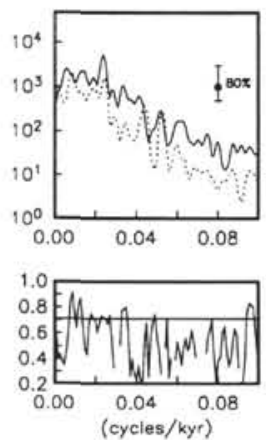

G. 1-2 ma
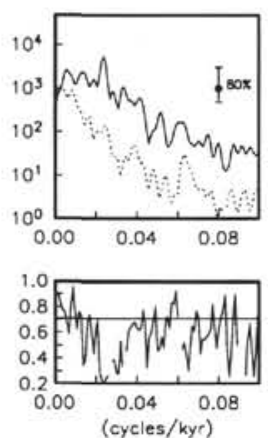

C. 2-3 ma
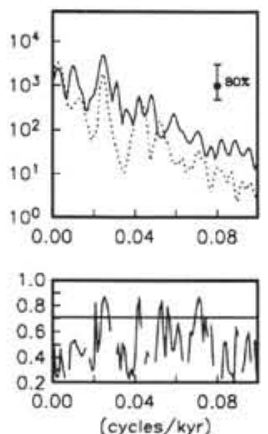

H. 2-3 ma
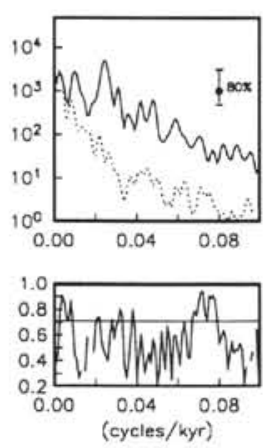

D. 3-4 ma
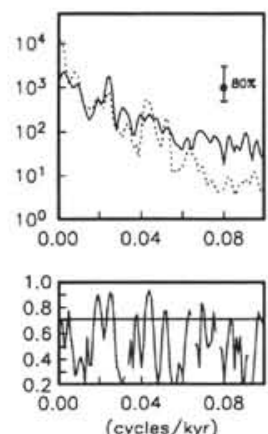

I. 3-4 ma
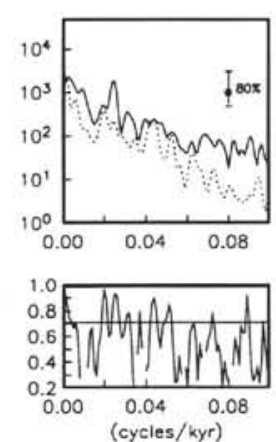

E. 4-4.6 ma
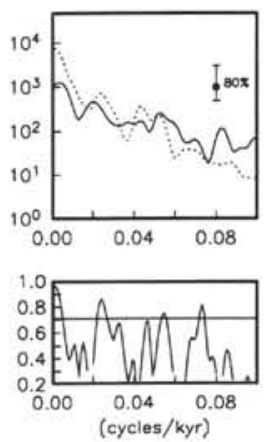

J. $4-4.6 \mathrm{mo}$
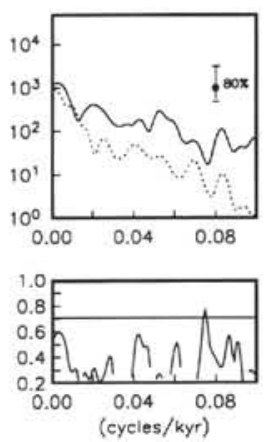

Figure 21. A-E. Power and coherence spectra for oxygen isotopes and \% $\mathrm{CaCO}_{3}$ EOF-1, for the 1-m.y. time slice amplitude time series given in Figure 13. Solid line indicates the EOF power spectra, dotted line is the insolation power spectrum. F-J. Power and coherence spectra for oxygen isotopes and EOF-2 for the amplitude time series given in Figure 13. Symbols are as described in the caption for Figure 10.

ate EOFs at orbital frequencies supports some level of carbonate-ice volume covariance over at least the past $4 \mathrm{~m} . \mathrm{y}$. Cross-spectral comparisons are given in Figure 21 and summarized in Table 7. Coherence between EOF-1 and $\delta^{18} \mathrm{O}$ at periods of 41,23 , and $19 \mathrm{k} . \mathrm{y}$, over the past $4 \mathrm{~m} . \mathrm{y}$. is significant at a 0.80 level. From 0 to $2 \mathrm{Ma}$, coherence at 100 k.y. periods is 0.87 to 0.91 , with a phase lag of EOF- 1 of $~ 16$ k.y. These results indicate that variability in carbonate and ice is coupled at low frequencies during at least the past 2 m.y. An 8- to 12-k.y. phase lag occurs between $\delta^{18} \mathrm{O}$ and equatorial Pacific carbonate sedimentation at periods of 41,23 , and $19 \mathrm{k} . y$. (Table 7 ), which is consistent with the previous results of Moore et al. (1977). In prePleistocene intervals, coherence between $\delta^{18} \mathrm{O}$ and both EOF-1 and EOF-2 time series is generally low, with the exception of the period from 3 to $4 \mathrm{Ma}$, where coherence is high at orbital frequencies.

EOF-2 and $\delta^{18} \mathrm{O}$ are coherent at 100 k.y. from 0 to $2 \mathrm{Ma}(0.94$ 0.96 ; Fig. 21), with a phase lag of 18 to 19 k.y. The presence of variability in EOF-2 at 100 k.y. that is coherent with 100-k.y. ice volume oscillations of the late Pleistocene, and that is at the same time uncorrelated to the 100-k.y. variability in EOF-1, reflects the response of different aspects of the carbonate system. The coherence between EOF-1 and $\delta^{18} \mathrm{O}$ may reflect a relationship between carbonate productivity and glacial/interglacial oscillations, while the coherence between EOF-2 and $\delta^{18} \mathrm{O}$ may be indicative of a correlation between carbonate dissolution and glacial/interglacial fluctuations. This result underscores the effectiveness of EOF analysis as a technique for partitioning uncorrelated modes of variability.

\section{Implications}

Taken at face value, the EOF patterns resolved above indicate a strong influence by surface ocean processes on eastern equatorial Pacific carbonate sedimentation. In every analysis, the equator is the focus of most of the variability in EOF-1, suggesting a relation to equatorial divergence and, thus, carbonate productivity. In the $\mathrm{CaCO}_{3}$ concentration EOFs alone, the possibility of opal dilution cannot be ruled out. However, the results from EOF analysis of carbonate MAR time series exclude the possibility that the equatorial signal resolved in EOF-1 is mainly associated with noncarbonate dilution. EOF-1 includes variability that is highly coherent with insolation variations. Frequency domain analyses suggest a coupling to surface ocean processes at a range of frequencies. Regional variability is stronger in the tilt and precession bands than at low frequencies.

One independent line of evidence supports changes in carbonate productivity as the primary factor controlling carbonate sedimentation. Radiolarian faunal data from intervals containing high and low carbonate concentrations, respectively, were studied by Pisias et al. (this volume). Radiolarians associated with increased productivity and stronger equatorial divergence correlate with decreased $\mathrm{CaCO}_{3}$, while radiolarians associated with warmer, tropical waters correlate with increased $\mathrm{CaCO}_{3}$. As carbonate concentration and carbonate mass flux are positively correlated, this indicates that increased opaline productivity coincides with decreased carbonate production in the equatorial Pacific, and vice versa. Lyle et al. (1988) arrived at similar conclusions in a late Pleistocene study of equatorial Pacific sedimentation. They postulated that oscillations in production of two planktonic communities dominate in equatorial Pacific surface waters, one community of both opal and calcite-secreting plankton, and one entirely opal. The carbonate fluctuations in the cores studied by Lyle et al. (1988) were demonstrated to have derived mainly from changes in carbonate flux out of the water column, rather than from carbonate dissolution.

An important result of this study is the constancy of the dominant mode of carbonate sedimentation and the apparent relationship to surface processes in the presence of other large-scale boundary condition changes. A similar result was found by Pisias et al. (this volume), who determined that fundamental relationships between 
carbonate sedimentation, radiolarian faunas, and equatorial surface circulation are constant over the past $6 \mathrm{~m}$.y. If dissolution were a primary influence on carbonate concentration, the deep water-mass reorganizations associated with closure of Panama and the onset of Northern Hemisphere glaciation should be evident in carbonate variability. The modeling study of Maier-Raimer et al. (1990) found no change in the strength of equatorial divergence associated with closure of the Panamanian isthmus. Similarly, Hays et al. (1987) did not see a decrease in equatorial divergence associated with this event. These results are consistent with the results implied by the spatial patterns of EOF-1. However, the spatial pattern of EOF-2 may reflect external boundary condition changes in addition to surface ocean processes.

Could changes in carbonate saturation state and associated carbonate dissolution be responsible for the variability resolved above? Although the EOF analyses strongly suggest that surface ocean processes are primary, is a dissolution signal embedded? To answer this, carbonate dissolution related to changes in the chemistry of the deep ocean must be considered, as well as dissolution related to regional organic carbon oxidation, a byproduct of increased productivity. Each of these dissolution processes is discussed below. In addition, comparison to other dissolution indicators is necessary.

If dissolution caused by global oceanic chemistry changes drives equatorial Pacific $\mathrm{CaCO}_{3}$ sedimentation, a pattern of variability similar to modern productivity gradients would not be expected. The water depths of five of the sites studied above (848-852; Table 1) fall within a $100-\mathrm{m}$ range. If dissolution were the dominant process and all other factors were held constant, these five sites would respond similarly to changes in corrosiveness of the overlying waters, and they would have approximately the same variance. However, variability over these sites is significant on time scales up to $20 \mathrm{k} . \mathrm{y}$. Archer's model (Archer, 1991 a) predicted that a very large gradient in carbonate saturation would be required over a depth interval of $200 \mathrm{~m}$ to account for central equatorial Pacific $\mathrm{CaCO}_{3}$ patterns by changes in ocean chemistry. This is unlikely given the relative homogeneity of the present-day gradient (Archer, 1991a). It is more unlikely that large corrosivity changes on precessional time scales would occur over an even smaller depth range.

If dissolution owing to global ocean chemistry variation is dominant, a correlation between water depth and carbonate sedimentation would be present. Because all of the sites are within the upper lysocline, records at deeper water depths would be expected to have more variability than the shallowest sites. The transects of EOF loadings over depth (Figs. 12B, 16B, 18B, 18D, 18F) indicate that the opposite is true for EOF-I. Sites 846 and 847, which are the shallowest sites, have on average higher loadings in EOF-1 for $\mathrm{CaCO}_{3}$ concentration and MAR than Sites 848 through 853, which are more than $400 \mathrm{~m}$ deeper. In some cases, such as the low-frequency band EOF loadings for $\mathrm{CaCO}_{3}$, no relationship with depth can be determined. The only instance where a positive correlation between EOF loadings and depth is seen is in $\mathrm{CaCO}_{3} \mathrm{EOF}-2$. Carbonate dissolution must be considered as a possible dominant factor determining the spatial pattern of EOF-2, and as one of several factors controlling EOF-1 of the low frequency band.

Variability in carbonate sedimentation at low frequencies may be related to carbonate dissolution. Evidence lies in the slightly lower gradients with latitude resolved in the low frequency EOFs relative to the tilt band and precession band EOFs. and the low spatial variability from 0 to 1,1 to 2 , and 4 to $5 \mathrm{Ma}$ (Figs. 17, 19, and 20). If true, then influence from dissolution is embedded in the spatial variability of $\mathrm{EOF}-1$ of $\mathrm{CaCO}_{3}$, because low frequency variance is dominant in all of the $\mathrm{CaCO}_{3}$ records, and EOF-I accounts for more than $50 \%$ of the total variance. Additional evidence comes from comparison of EOF-1 with benthic $\delta^{18} \mathrm{O}$, where at low frequencies, variations in ice volume and EOF-1 are coherent (Fig. 21). However, with the exception of the time intervals from 3 to $4 \mathrm{Ma}$ and 5 to $6 \mathrm{Ma}$, the low-pass filtered $\mathrm{CaCO}_{3}$ EOFs show a correlation with latitude, and the highest loadings are focused on the equator. Thus, even at low frequencies, surface oceanographic processes exert influence on carbonate sedimentation.

If dissolution is a primary component affecting all Leg 138 sites to the same degree, an attenuation as a function of carbonate sedimentation rate can be expected. If all other factors affecting carbonate sedimentation are held constant except for carbonate sedimentation rates, higher sedimentation rate sites will show less of a response to the same amount of changes in dissolution. This effect was modeled by Pisias and Prell (1985), using carbonate records from DSDP Leg 85 sites. At the Leg 138 sites, the maximum carbonate accumulation rates are at the equatorial sites, and the minimum carbonate accumulation rates are located away from the equator (Sites 848,852 , and 853). According to the Pisias and Prell model, dissolution should exert a stronger control on the variability in Sites 848,852 , and 853 relative to equatorial Sites 849,850 , and 851 . Although inconsistent with EOF-1, such a pattern is consistent with EOF-2 on the western transect. This is another line of evidence supporting EOF-2 as an indicator of carbonate dissolution.

Another line of evidence that argues against dissolution as a primary factor driving carbonate fluctuations at Leg 138 sites is a comparison to dissolution indexes. If dissolution is significant, a correlation between carbonate variability and dissolution indexes might be evident. Dissolution indexes, as estimated from foraminiferal fragmentation data, have been generated for Site 847 (Murray, et al., this volume) and Site 846 (Le et al., this volume). Sites 846 and 847 have very high loadings in EOFs 1 and 2 for $\mathrm{CaCO}_{3}$ concentration and MAR, but comparison of these records to fragmentation data shows little relationship. In some instances, carbonate and fragmentation indexes appear to be positively correlated, and in other instances, a negative correlation is evident. The correlation coefficients between the fragmentation records and carbonate concentration, carbonate $\mathrm{MAR}$, and carbonate EOFs, respectively, are close to zero. Because of other evidence suggesting that EOF- 2 of carbonate concentration reflects dissolution processes, this result may indicate that fragmentation indexes are not the best indicators of carbonate loss resulting from dissolution.

How important is the role of carbonate dissolution driven by organic carbon respiration? Equatorial sites located in regions of higher productivity would lie under waters more undersaturated in $\mathrm{CO}_{3}=$ than sites off of the equator, where production is lower. Accordingly, lower $\mathrm{CO}_{3}=$ concentration is documented beneath the equator in the eastern Pacific (Broecker and Peng, 1982, p.77). If this type of dissolution is a primary control on carbonate sedimentation, then most variability could be expected to be coupled to equatorial divergence, where productivity is highest. Archer (1991b) modeled the effect of variations of organic carbon degradation on lysocline shape. For the last glacial maximum, Archer (1991a) determined that the increase in carbonate accumulation observed by Farrell and Prell (1989) in the central equatorial Pacific in theory can be generated by decreasing the ratio of organic carbon to calcite and, thereby, diminishing respiration-driven dissolution. However, organic carbon accumulation in the equatorial Pacific coincides with higher carbonate accumulation during the Pleistocene (Doose et al., this volume; Lyle et al., 1988; Pedersen, 1983). By extension to the late Neogene, this rules out organic carbon respiration as a single dominating factor. However, modeling the effect of changes in the ratio of organic carbon to calcite flux will help to determine the role of this process in determining the spatial patterns resolved here.

If both global deep ocean chemistry changes and organic carboninduced dissolution are considered together, then it becomes clear why resolving a single dissolution mode is difficult. One dissolution process would be coupled to water depth, and the other process would 
be coupled to the surface productivity, all other factors held constant. In addition, while high productivity may lead to increased dissolution in one region of the equatorial Pacific, the increase in rain rate of material could lead to increased preservation in another region. As noted by Archer (1991b), the competition of these two effects may make resolution of either one of them difficult, especially if they are operating on the same time scales.

As noted previously, the spatial distribution of $\mathrm{CaCO}_{3} \mathrm{EOF}-2$ may suggest a relationship to these multiple carbonate dissolution processes. For instance, if high oceanic productivity at the eastern boundary is associated with high loadings of EOF-2 on the eastern transect. this may indicate high dissolution induced by organic carbon. The same high productivity might lead to decreased dissolution at offequator sites on the $110^{\circ} \mathrm{W}$ transect because of increased chances for preservation of carbonate. This might explain the out-of-phase relationship between eastern and western sites. Although amplitude time series of EOF-2 are not correlated to foraminiferal fragmentation data, there is evidence for a correlation with water depth (Fig. 12D). On the $110^{\circ} \mathrm{W}$ transect, the loadings of EOF-2 are consistent with influence from dissolution. However, the absence of a relationship to the fragmentation indexes remains puzzling.

One can make a similar argument regarding the role of noncarbonate dilution in controlling the spatial pattern of $\mathrm{CaCO}_{3}$ EOF-2. Because the spatial pattern of EOF- 2 in $\mathrm{CaCO}_{3}$ concentration is different from the spatial pattern of EOF-2 of carbonate MAR, the concentration data must record a different process. The spatial pattern of $\mathrm{CaCO}_{3}$ concentration EOF-2 might be indicating dilution related to opal production in the eastern transect sites, and also carbonate dissolution in the off-equator sites on the western transect. This possibility can be tested with records of opal and noncarbonate, non-opal accumulation and with opaline faunal counts, such as that of Pisias et al. (this volume).

The patterns resolved in EOF-2 of carbonate concentration may indicate a change in oceanographic boundary conditions near 3 to 4 Ma. A stepwise change in the amplitude time series of EOF-2 (Fig. 9) occurs at this time, and a change in the spatial pattern of EOF-2 in the time slices occurs between 3 to $4 \mathrm{Ma}$ and 4 to $5 \mathrm{Ma}$. These changes may be associated with closure of the Panamanian isthmus. A modeling study (Maier-Raimer et al., 1990) suggested that the closure of the Isthmus of Panama at about 3 to $4 \mathrm{Ma}$ was related to significant changes in the intensity of deep ocean circulation and, thereby, deep ocean chemistry. The spatial pattern of EOF-2 may indicate a response of carbonate sedimentation consistent with this boundary condition change.

\section{CONCLUSIONS}

1. Spatial patterns in sediment composition in the eastern equatorial Pacific exhibit variability common to all of Leg 138 Sites 846 through 853 , as well as variability that is associated with latitude. Large spatial variability is present over the past $6 \mathrm{~m} . \mathrm{y}$. on time scales from 1 m.y. to less than 10 k.y. The spatial patterns are remarkably consistent over the past 6 m.y. Although differences between individual time slices are evident, the fundamental spatial pattern that represents the bulk of the variability in the carbonate system is consistent over time periods in which large boundary condition changes take place. This implies a constant forcing mechanism of variability in carbonate sedimentation over the past 6 m.y.

2. Two independent modes of variability account for more than $70 \%$ of the variance in carbonate concentration and carbonate accumulation records over the past 6 m.y. The first mode, EOF-1, is coupled to the equator and is coherent with insolation changes. This pattern of variability appears to be associated with surface ocean processes. The second mode of variability in carbonate sedimentation may be associated with carbonate dissolution over the past 4 m.y. Coherence between carbonate EOF-2 and insolation is low.

3. Variability in carbonate sedimentation differs as a function of frequency, but in the precession band, the tilt band, and the low frequency band, high regional variability allows one to infer a coupling to surface ocean processes. Precession band variability displays the highest coupling to the equator, tilt band variability indicates stronger importance of Site 852 at $6^{\circ} \mathrm{N}$, and variability in carbonate sedimentation at low frequencies displays the least coupling to equatorial processes.

4. A correlation of the loadings of EOF-1 of carbonate concentration and mass accumulation with latitude implies a strong linkage of carbonate sedimentation to surface ocean processes. The absence of a correlation between EOF-1 loadings and depth suggests that global alkalinity-induced dissolution is not dominant. The loadings of EOF2 do indicate a relationship with water depth, suggesting that dissolution may play a role in forcing this mode of variability.

5. Benthic $\delta^{18} \mathrm{O}$ and carbonate are positively correlated throughout the past $4 \mathrm{~m} . y$., with increased carbonate associated with positive $\delta^{18} \mathrm{O}$. Over the past $4 \mathrm{~m} . \mathrm{y}$., the dominant mode of variability in carbonate concentration (EOF-1) is coherent with Site $849 / 846 \delta^{18} \mathrm{O}$ at periods of 41,23 , and $19 \mathrm{k} . \mathrm{y}$. The second independent mode of carbonate variability (EOF-2) is coherent with $\delta^{18} \mathrm{O}$ at 100 k.y. from 0 to $2 \mathrm{Ma}$. The two independent modes of variability observed in the carbonate system each have linear relationships to $\delta^{18} \mathrm{O}$, but at different frequencies and/or phases. This implies linkages with variability in ice volume in both modes of carbonate variability.

6. Modeling of dissolution and dilution processes combined with EOF analyses and comparison to faunal and isotopic indicators from Leg 138 sites can provide additional constraints to the oceanographic interpretations from the EOFs presented here. Parameters indicating surface ocean processes, such as radiolarian and foraminiferal census data, will be of use for determining the phase of the carbonate response with respect to insolation. Parameters that represent spatially coherent deep ocean changes, such as benthic isotopes, will constrain the spatial variance in the phase of the carbonate response.

\section{ACKNOWLEDGMENTS}

We thank D. Murray, J. Farrell, and J. Le for sharing fragmentation data and the rest of the Leg 138 Shipboard Scientific Party as well for lively discussion of this work as it developed. The authors gratefully acknowledge Tj. van Andel, W.F. Ruddiman, and T.D. Herbert for critical reviews of this manuscript. A JOI-USSAC Ocean Drilling Graduate Fellowship to T. Hagelberg provided the opportunity for much of this work to take place. This study was supported by NSF Grant OCE-9216929 to T. Hagelberg and N. Pisias.

\section{REFERENCES}

Adelseck, C.G., Jr., and Anderson, T.F., 1978. The late Pleistocene record of productivity fluctuations in the eastern equatorial Pacific Ocean. Geology, 6:388-391.

Archer, D.E., 1991a. Equatorial Pacific calcite preservation cycles: production or dissolution? Paleoceanography, 6:561-571. 17050 .

Arrhenius, G., 1952. Sediment cores from the east Pacific. Rep. Swed. DeepSea Exped. 1947-1948, 5:189-201.

Berger, A., and Loutre, M.F., 1988. New insolation values for the climate of the last 10 million years. Inst. d'Astron. Geophys. G. Lemaitre, Univ. Cath. de Louvain, Louvain-la-Neuve, Belgium, Sci. Rep., 1988/13.

Berger, W.H., 1973. Deep-sea carbonates: Pleistocene dissolution cycles. $J$. Foraminiferal Res., 3:187-195. 
Boyce, R.E., 1976. Definitions and laboratory techniques of compressional sound velocity parameters and wet-water content, wet-bulk density, and porosity parameters by gravimetric and gamma ray attenuation techniques. In Schlanger, S.O., Jackson, E.D., et al., Init. Repts. DSDP, 33: Washington (U.S. Govt. Printing Office), 931-958.

Broecker, W.S., and Peng, T.-H., 1982. Tracers in the Sea: Palisades, NY (Eldigio Press).

Cox. A., and Engebretson, D., 1985. Change in motion of the Pacific plate at 5 Myr BP. Nature, 313:472-474.

Farrell, J.W., and Prell, W.L., 1989. Climatic change and $\mathrm{CaCO}_{3}$ preservation: an 800,000 year bathymetric reconstruction from the central equatorial Pacific Ocean. Paleoceanography, 4:447-466.

, 1991. Pacific $\mathrm{CaCO}_{3}$ preservation and $\delta^{18} \mathrm{O}$ since $4 \mathrm{Ma}$ : paleoceanic and paleoclimatic implications. Paleoceanography, 6:485-498.

Finney, B.P., Lyle, M.W., and Heath. G.R., 1988. Sedimentation at MANOP Site H (eastern equatorial Pacific) over the past 400,000 years: climatically induced redox variations and their effects on transition metal cycling. Paleoceanography, 3:169-189.

Hagelberg, T., Shackleton, N.. Pisias, N., and Shipboard Scientific Party, 1992. Development of composite depth sections for Sites 844 through 854 . In Mayer, L., Pisias, N., Janecek, T., et al., Proc. ODP, Init. Repts., 138 (Pt. 1): College Station, TX (Ocean Drilling Program), 79-85.

Hays, J.D., Saito, T., Opdyke, N.D., and Burckle, L.R., 1969. Pliocene-Pleistocene sediments of the equatorial Pacific: their paleomagnetic, biostratigraphic, and climatic record. Geol. Soc. Am. Bull., 80:1481-1513.

Hays, P.E., Pisias, N.G., and Roelofs, A.K., 1987. Paleoceanography of the eastern equatorial Pacific during the Pliocene: a high-resolution radiolarian study. Paleoceanography, 4:57-73.

Heath, G.R., and Culberson, C., 1970. Calcite: degree of saturation, rate of dissolution and the compensation depth in the deep oceans. Geol. Soc. Am. Bull., 81:3157-3160.

Heinze, C., Maier-Reimer, E., and Winn, K., 1991. Glacial pCO 2 reduction by the world ocean: experiments with the Hamburg carbon cycle model. Paleoceanography, 6:395-430.

Herbert, T.D., and Mayer, L.A., 1991. Long climatic time series from sediment physical property measurements, J. Sediment. Petrol., 61:1089-1108.

Imbrie, J., Boyle, E.A., Clemens, S.C., Duffy, A., Howard, W.R., Kukla, G., Kutzbach, J., Martinson, D.G., McIntyre, A., Mix, A.C., Molfino, B., Morley, J.J., Peterson, L.C., Pisias, N.G., Prell, W.L., Raymo, M.E., Shackleton, N.J., and Toggweiler, J.R., 1993. On the structure and origin of major glaciation cycles, 1. Linear responses to Milankovitch forcing. Paleoceanography, 7:701-738.

Jenkins, G.M., and Watts, D.G., 1968. Spectral Analysis and Its Applications: San Francisco (Holden Day).

Luz, B., and Shackleton, N.J., 1975. $\mathrm{CaCO}_{3}$ solution in the tropical east Pacific during the past 130,000 years. In Sliter, W.V., Bé, A.W., and Berger, W.H. (Eds.), Dissolution of Deep-Sea Carbonates. Spec. Publ. Cushman Found. Foraminiferal Res., 13:142-150.

Lyle, M.W., Murray, D.W., Finney, B.P., Dymond, J., Robbins, J.M., and Brooksforce, K., 1988. The record of late Pleistocene biogenic sedimentation in the eastern tropical Pacific Ocean. Paleoceanography, 3:39-59.

Maier-Reimer, E., Mikolajewicz, U., and Crowley, T., 1990. Ocean general circulation model sensitivity experiment with an open Central American Isthmus. Paleoceanography, 5:349-366.

Mayer, L., Pisias, N., Janecek, T., et al., 1992. Proc. ODP, Init. Repts., 138 (Pts. 1 and 2): College Station, TX (Ocean Drilling Program).

Mayer, L.A., 1978. Deep sea carbonates: acoustic, physical, and stratigraphic properties. J. Sediment. Petrol., 49:819-836.

, 1991. Extraction of high-resolution carbonate data for paleoclimatic reconstruction. Nature, 352:148-151.

Mix, A.C., 1989. Pleistocene paleoproductivity: evidence from organic carbon and foraminifer species. In Berger, W.H., Smetacek, V.S., and Wefer, G.
(Eds.), Productivity of the Oceans: Present and Past: New York (Wiley), 313-340.

Moore, T.C., Pisias, N.G., and Dunn, D.A., 1982. Carbonate time series of the Quaternary and late Miocene sediments in the Pacific Ocean: a spectral comparison. Mar. Geol., 46:217-233.

Moore, T.C., Jr., Pisias, N.G., and Heath, G.R., 1977. Climate changes and lags in Pacific carbonate preservation, sea surface temperature and global ice volume. In Anderson, N.R., and Malahoff, A. (Eds.), The Fate of Fossil Fuel $\mathrm{CO}_{2}$ in the Oceans: New York (Plenum), 145-165.

Murray, D.W., 1987. Spatial and temporal variations in sediment accumulation in the central tropical Pacific [Ph.D. dissert.]. Oregon State Univ., Corvallis, OR.

Parker, F.L.. and Berger, W.H., 1971. Faunal and solution patterns of planktonic Foraminifera in surface sediments of the South Pacific. Deep-Sea Res. Part A, 18:73-107.

Pedersen, T.F., 1983. Increased productivity in the eastern equatorial Pacific during the last glacial maximum (19,000 to $14,000 \mathrm{yr}$ B.P.). Geology, 11:16-19.

Pisias, N.G., Mayer, L.A., Shackleton, N.J., Hagelberg, T.K., Mix, A.C., and ODP Leg 138 Shipboard Scientific Party, 1992. Temporal response of the east Pacific carbonate system to orbital forcing: evidence from Site 849. Leg 138. Proc, 4th Int. Conf. on Paleoceanography, Kiel, Germany, 228. (Abstract)

Pisias, N.G.. and Moore, T.C., Jr., 1981. The evolution of Pleistocene climate: a time series approach. Earth Planet. Sci. Lett., 52:450-458.

Pisias, N.G., and Prell, W.L., 1985. Changes in calcium carbonate accumulation in the Equatorial Pacific during the late Cenozoic: evidence from HPC Site 572. In Sundquist, E.T., and Broccker, W.S. (Eds.), The Carbon Cycle and Atmospheric $\mathrm{CO}_{2}$ : Natural Variations Archean to Present. Am. Geophys. Union, 443-454.

Prahl, F.G., Muehlhausen, L.A., and Lyle, M., 1989. An organic geochemical assessment of oceanographic conditions at MANOP site $\mathrm{C}$ over the past 26,000 years. Paleoceanography, 4:5:495-510.

Preisendorfer, R.W., 1988. Principal Component Analysis in Meterology and Oceanography: Amsterdam (Elsevier).

Ravelo, A.C.,Pacanowski, R., and Philander, S.G.H., 1992. Changes in the east tropical Pacific seasonal thermocline over the past 2.5 ma: observation and model comparison. Eos, 73:43:249. (Abstract)

Raymo, M.E., Ruddiman, W.F., Backman, J., Clement, B.M., and Martinson, D.G., 1989. Late Pliocene variation in Northern Hemisphere ice sheets and North Atlantic deep water circulation. Paleoceanography, 4:413-446.

Raymo, M.E., Ruddiman, W.F., and Froelich, P.N., 1988. Influence of late Cenozoic mountain building on ocean geochemical cycles. Geology, I6:649-653.

Rea, D.K., Pisias, N.G., and Newberry. T., 1991. Late Pleistocene paleoclimatology of the central Equatorial Pacific: flux patterns of biogenic sediments. Paleoceanography, 6:227-244.

Ruddiman, W.F., Raymo, M.E., Martinson, D.G., Clement, B.M., and Backman, J., 1989. Pleistocene evolution: Northern Hemisphere ice sheets and North Atlantic Ocean. Paleoceanography, 4:353-412.

Shackleton, N.J., and Shipboard Scientific Party, 1992. Sedimentation rates: toward a GRAPE density stratigraphy for Leg 138 carbonate sections. In Mayer, L., Pisias, N., Janecek, T., et al., Proc. ODP, Init. Repts., 138 (Pt. 1): College Station, TX (Ocean Drilling Program), 87-91.

van Andel, T.H., Heath, G.R., and Moore, T.C., 1975. Cenozoic history and paleoceanography of the central equatorial Pacific Ocean. Mem.-Geol. Soc. Am., 143.

Date of initial receipt: 5 February 1993

Date of acceptance: 26 July 1993

Ms 138SR-116 